Article

\title{
Synthesis and Photoluminescent Properties of Geometrically Hindered cis-Tris(diphenylaminofluorene) as Precursors to Light-Emitting Devices
}

\author{
Nam-Goo Kang ${ }^{1}$, Ken Kokubo ${ }^{2}$, Seaho Jeon ${ }^{1}$, Min Wang ${ }^{1}$, Chang-Lyoul Lee ${ }^{3}$, \\ Taizoon Canteenwala ${ }^{1}$, Loon-Seng Tan ${ }^{4}$ and Long Y. Chiang ${ }^{1, *}$
}

1 Department of Chemistry, Institute of Nanoscience and Engineering Technology, University of Massachusetts Lowell, Lowell, MA 01854, USA;

E-Mails: papyrus92@gmail.com (N.-G.K.); seaho_jeon@uml.edu (S.J.); wangmin81@gmail.com (M.W.); taizoonc@hotmail.com (T.C.)

2 Division of Applied Chemistry, Graduate School of Engineering, Osaka University, Suita, Osaka 565-0871, Japan; E-Mail: kokubo@chem.eng.osaka-u.ac.jp

3 Advanced Photonics Research Institute, Gwangju Institute of Science and Technology, Gwangju 500-712, Korea; E-Mail: vsepr@gist.ac.kr

4 AFRL/RXBN, Air Force Research Laboratory, Wright-Patterson Air Force Base, Dayton, OH 45433, USA; E-Mail: Loon-Seng.Tan@wpafb.af.mil

* Author to whom correspondence should be addressed; E-Mail: Long_Chiang@uml.edu; Tel.: +1-978-934-3663; Fax: +1-978-934-3013.

Academic Editor: Pall Thordarson

Received: 12 January 2015 / Accepted: 4 March 2015 / Published: 13 March 2015

\begin{abstract}
A novel highly luminescent tris-fluorenyl ring-interconnected chromophore tris(DPAF-C9) was synthesized using a $C_{3}$ symmetrical triaminobenzene core as the synthon. This structure bears three light-harvesting 2-diphenylamino-9,9-dialkylfluorenyl (DPAF) ring moieties with each attached by two branched 3',5',5'-trimethylhexyl ( $\left.\mathrm{C}_{9}\right)$ arms. A major stereoisomer was chromatographically isolated and characterized to possess a 3D structural configuration of cis-conformer in a cup-form. Molecular calculation at B3LYP/6-31G* level revealed the unexpected stability of this cis-cup-conformer of tris(DPAF-C9) better than that of the stereoisomer in a propeller-form and the trans-conformer. The structural geometry is proposed to be capable of minimizing the aggregation related self-quenching effect in the condensed phase. Fluorescence emission wavelength of tris(DPAF-C9) was found to be in a close range to that of PVK that led to its potential uses as the secondary
\end{abstract}


blue hole-transporting material for enhancing the device property toward the modulation of PLED performance.

Keywords: cis-tris(diphenylaminofluorene); light-harvesting nanostructure; light emitting chromophore; geometrically hindered diphenylaminofluorene; nonplanar stereoisomer

\section{Introduction}

Organic donor fluorophores having extended polarizable ring-branching conjugations in their structure often exhibit good efficiency in photoluminescence that makes them suitable as active components in a number of materials applications, such as optoelectronic devices [1], light-emitting diode (OLED/PLED) cells for flat-panel display [2-4], nonlinear optical (NLO) materials for optical limiting (OL) [5], 3D nano/microfabrication [6], one-photon $(1 \gamma)$ or two-photon (2 $\gamma)$ fluorescence-based optical bio-imaging and labeling substrates for medical diagnosis [7,8], biosensors [9-11], and photo-diagnosis/photodynamic sensitizers for PDT treatments [12,13]. The former four applications involve thin-film device or coating fabrication processes in a solid form of the material. Therefore, it is crucial for organic donor fluorophores to exhibit either an ultrafast photoresponsive excited state population (for NLO/OL) or intense electroluminescence (for OLED/PLED) in the solid state to increase the performance efficiency. However, these physical property characteristics of fluorophores are often difficult to manage and predict in the thin solid film owing to their strong tendency to aggregate among $\pi$-conjugated planar aromatic moieties that cause either the concentration- or self-quenching effect of excited states or luminescence in the condensed phase. Only certain highly bulky and geometrically hindered $\pi$-conjugated chromophore examples possessing restricted or distorted intramolecular rotation bonding units with steric hindrance were found to be fluorescence-active in different physical forms. This led to the retention or increase of fluorescence emission instead of suffering the high concentration-quenching effect upon either one-photon [14] or two-photon [15,16] excitation in the aggregated state as compared with that in the solution. Accordingly, a significant structural modification of organic fluorophores is necessary in order to generate appreciable solid-state nonlinear optical absorptivity, photoluminescence (PL), and electroluminescence (EL) and improve the corresponding quantum yields.

Structurally branched and dendrimeric design of molecular fluorophores was demonstrated to achieve a large value of simultaneous two-photon absorption (2PA) cross sections during photoexcitation in the NIR region that led to the release of up-converted fluorescence in visible wavelengths. These photophysical properties were associated with the unique nonlinear optical and $2 \gamma$-photodynamic sensitizing features. A number of structural variation were demonstrated, including a molecular approach in a multibranched [17,18], octapolar [19-22], dendrimeric [23-26], or spiro [27] pattern. Branched and $\pi$-conjugated fluorophores with semiconducting charge-transport, light-emission, and high glass-transition temperature characteristics were also of high interest as novel host materials for light-emitting diodes [28]. They consist of a luminescent chromophore at the core region with highly branched conjugated dendron branching side-groups that gave enhanced effects of light emission and charge transport [29]. Using the similar approach, we proposed a molecular configuration with 
geometrically branched chromophores using a $C_{3}$ symmetrical 1,3,5-triaminobenzene ring as the center core for the connection of three fused 2-diphenylaminofluorene moieties, leading to a new class of tris(DPAF-C9) 7 structure (Scheme 1). The branched donor fluorophore 7 having high torsional stress at the central core region forces all fluorene chromophore groups located at the outer-edge area to a non-coplanar 3D-configuration. This should minimize the direct contact or $\pi$-stacking of the fluorene ring with each other during molecular aggregation and prevent the excimer formation while allows intermolecular interactions of photoluminescent fluorene moieties. We expect well-defined intramolecular and intermolecular space-separation of all diphenylaminofluorene moieties from each other, owing to the pre-designed geometrical configuration around the central benzene ring, should effectively increase the light-exposure surface area of the material and minimize the self-quenching effect of its photoexcited state in a high-concentration form or solids.

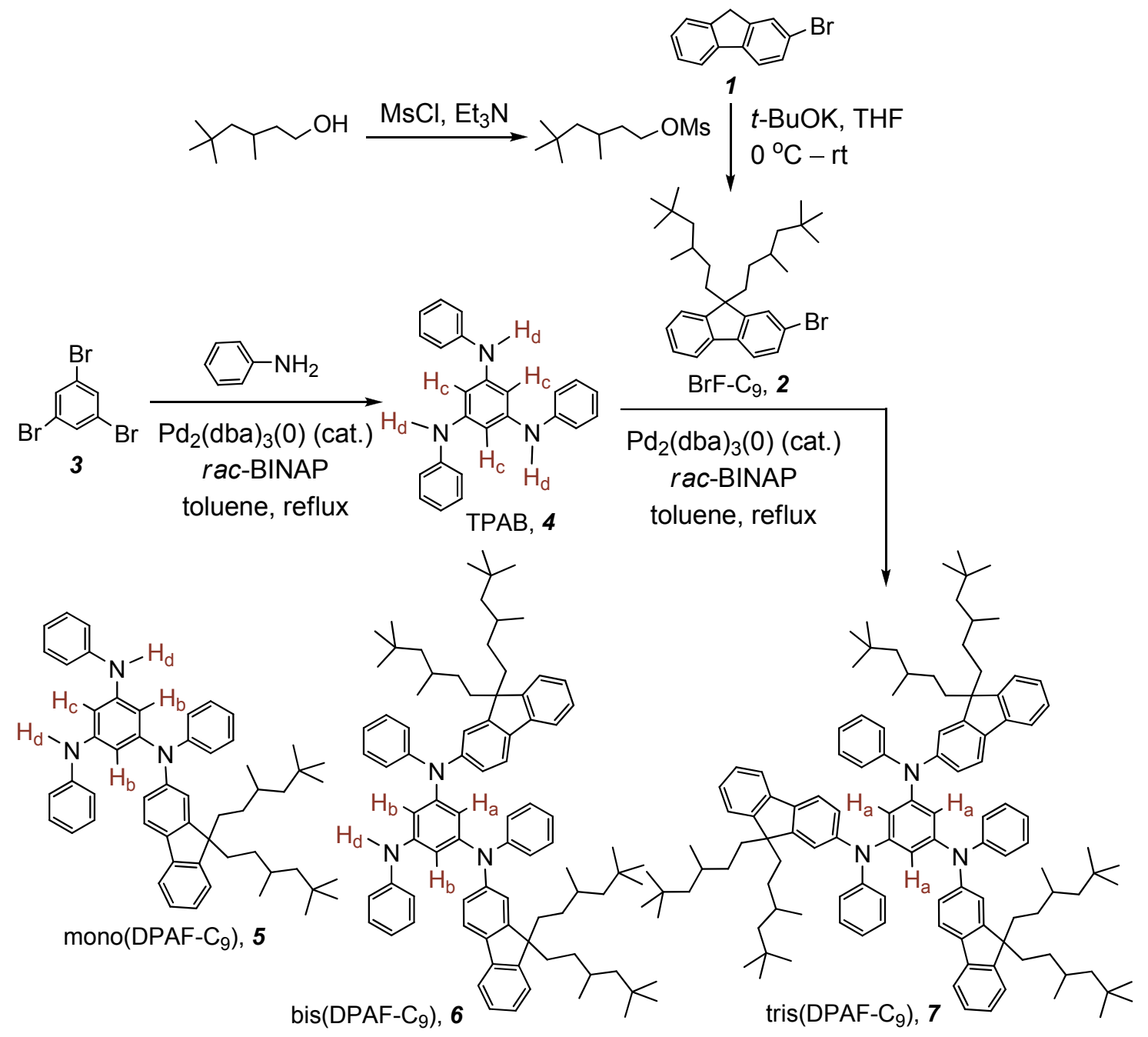

Scheme 1. Synthetic route of tris(DPAF-C9) 7.

\section{Results and Discussion}

Photophysical properties associated with highly enhanced NLO absorption cross sections in the NIR region were achieved by the attachment of one or multiple 9,9'-dialkyl-2-diphenylaminofluorene moieties on a spherical $\mathrm{C}_{60}$ molecule using a periconjugated keto-bridging unit [30]. It also indicated 
the improvement of light harvesting efficiency by using hindered and branched 3',5',5'-trimethylhexyl (C9) arms to maintain the space-separation of fluorophores intramolecularly within the nanostructure and intermolecularly during possible cluster formation or aggregation in solution. These conclusions became the basis of our new molecular design of tris(DPAF-C9) analogous structures 5-7. In this case, the central benzene ring was shared by two and three phenylaminofluorene antenna unit in the molecular structure of 6 and 7, respectively, as a fused dendron. Since tris(DPAF-C9) 7 is highly fluorescence emissive, it can be utilized as a charge-injecting host fluorophore for the study of PLED devices.

The synthetic route for the preparation of asymmetrical chromophore mono(DPAF-C9) 5 and bis(DPAF-C9) 6, and $C_{3}$-symmetrical chromophore tris(DPAF-C9) 7, having both dialkylated fluorenyl and phenyl groups on each nitrogen atom of a central 1,3,5-triaminobenzene core was performed, as shown in Scheme 1. Alkylation of 2-bromofluorene 1 with mesylated 3,5,5-trimethylhexanol giving 2-bromo-9,9-bis(3',5',5'-trimethylhexyl)fluorene, $\mathrm{BrF}_{-} \mathrm{C}_{9} \mathbf{2}$, was carried out using potassium $t$-butoxide as a base. The reaction proceeded in a high yield of $90 \%$. The synthesis of 1,3,5-tris(phenylamino)benzene, TPAB 4, was reported previously [31,32]. However, in order to improve the yield of product, we employed an modified procedure of the palladium-catalyzed amination reaction with tris(dibenzylideneacetone)dipalladium $(0)\left[\mathrm{Pd}_{2}(\mathrm{dba})_{3}(0)\right]$ as the catalyst. The reaction was carried out by using five equivalents (excess) of aniline in respect to the quantity of 1,3,5-tribromobenzene 3 in the presence of $r a c-2,2$-bis(diphenylphosphino)-1,1'-binaphthyl (rac-BINAP) that resulted in a good tendency for the tris-product formation. Accordingly, a higher yield of 4 in $75 \%$ was obtained. A similar palladium-catalyzed amination was also applied in the next step synthesis. For instance, the reaction of $\mathrm{TPAB}$ with six equivalents of $\mathrm{BrF}_{-} \mathrm{C}_{9}$ in dry toluene at refluxing temperature for a period of $72 \mathrm{~h}$ was conducted to afford the final product tris(DPAF-C9) 7 . The crude product of 7 was then purified subsequently by column chromatography (silica gel) using only hexane and followed by hexane-ethyl acetate (9:1) as the eluent to give light yellow solids or clear thick sticky gel-like paste, while residual solvents are present, in a yield of $88 \%$.

For the synthesis of asymmetrical fluorophores, a different equivalent ratio of starting materials TPAB and BrF-C9 in 1:2 was applied for the preparation of bis(DPAF-C9) 6 and in 1:1 for the synthesis of mono(DPAF-C 9 ) 5 . In the case of the compound $\mathbf{6}$, similar reaction conditions as those for 7 in dry toluene were performed to give the product bis(DPAF-C 9 ). The crude thick liquid of 6 was purified by column chromatography $\left(\mathrm{SiO}_{2}\right)$ using hexane-ethyl acetate $(9: 1)$ as the eluent to yield white to light yellow glassy solids in 52\%. For the synthesis of mono(DPAF-C9) 5, a shorter solvent refluxing period of $48 \mathrm{~h}$ was used for the reaction of TPAB with one equivalent of 2 in dry toluene, giving the product of mono(DPAF-C9) 5 as white to light yellow glassy solids in a yield of $68 \%$ after column chromatography $\left(\mathrm{SiO}_{2}\right)$ purification using hexane-ethyl acetate $(9: 1)$ initially and then $7: 3$ as the eluent. All products 5, 6, and 7 were found to be photosensitive in the presence of electrophilic solvents and stable as a dry solid. Therefore, dark conditions were necessary during the workup and purification procedures.

Structural characterization of $\mathbf{5}, \mathbf{6}$, and $\mathbf{7}$ was made using various spectroscopic techniques. By comparison between the IR spectra of tris(DPAF-C9) 7 and TPAB, the introduction of dialkylated fluorenyl moiety to 4 was clearly confirmed by the appearance of strong aliphatic $\mathrm{C}-\mathrm{H}$ stretching vibration bands centered at $2953 \mathrm{~cm}^{-1}$ (supporting information) that was absent for TPAB. It also accompanied with several characteristic bands at 3063 and $1583 \mathrm{~cm}^{-1}$ assigned, for aromatic C-H 
stretching and $\mathrm{C}=\mathrm{C}$ absorption, respectively. Anti-symmetric deformations of $\mathrm{CH}_{3}$ groups and scissor vibrations of $\mathrm{CH}_{2}$ groups appeared as medium intensity bands centered around 1493 (s) and $1450 \mathrm{~cm}^{-1}$, while symmetric deformations of $\mathrm{CH}_{3}$ groups exhibited the absorption around $1363(\mathrm{~m}) \mathrm{cm}^{-1}$. Two other bands at $1294(\mathrm{~m})$ and $1249(\mathrm{~m})$ were assigned to the asymmetric stretching vibrations of C-N-C moieties. Close resemblance of these IR absorption bands was observed for both mono(DPAF-C9) 5 and bis(DPAF-C9) 6 indicating high similarity of functional groups consisting of DPAF-C 9 and TPAB moieties. All compounds 5-7 showed strong C-H out-of-plan deformation bands at 756 and $711 \mathrm{~cm}^{-1}$, for example, for 7. Furthermore, systematic decrease in intensity of the broad N-H absorption band centered at 3403 and $3375 \mathrm{~cm}^{-1}$ for TPAB to $3396 \mathrm{~cm}^{-1}$ for $\mathbf{5}, 3402 \mathrm{~cm}^{-1}$ for $\mathbf{6}$, and complete disappearance for 7 , indicated clearly the corresponding progressive amination of fluorenyl moieties (F-C9) from 5 to 7.

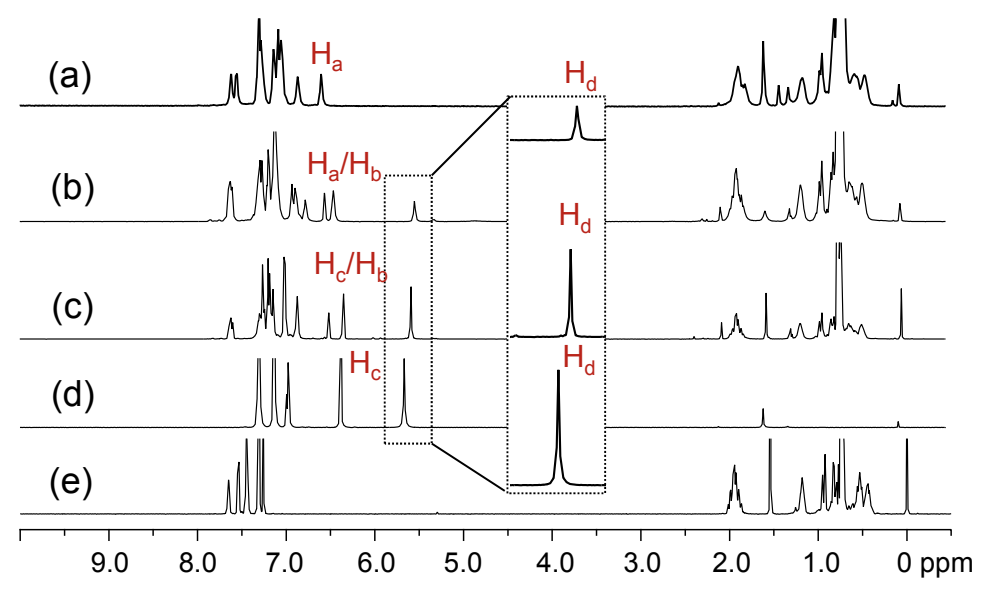

Figure 1. ${ }^{1} \mathrm{H}-\mathrm{NMR}$ spectra of (a) tris(DPAF-C9) 7, (b) bis(DPAF-C9) 6, (c) mono(DPAF-C9) 5, (d) TPAB 4, and (e) BrF-C9 2.

${ }^{1} \mathrm{H}-\mathrm{NMR}$ spectra of the precursor molecules $\mathrm{TPAB}$ and $\mathrm{BrF}_{-} \mathrm{C}_{9}$ were used as the reference, as shown in Figure 1d,e, for the comparison with those of mono-, bis-, and tris(DPAF-C9). The most critical evidence of the sequential attachment of 9,9-bis(3',5',5'-trimethylhexyl)fluorene dendrons to 4 was given by the systematic decrease in the integrated intensity ratio of the singlet signal at $\delta 5.67$, assigned for the chemical shift of $\mathrm{N}-\mathrm{H}\left(\mathrm{H}_{\mathrm{d}}\right)$ protons of TPAB (Figure 1d). The peak intensity of this peak matched well with the proton ratio of $\mathrm{H}_{\mathrm{d}}$ as two, one, and zero for 5 (at $\delta 5.56$, Figure 1c), 6 (at $\delta 5.52$, Figure 1b), and 7 (Figure 1a), respectively. The spectra also indicated the corresponding ratio increase of $\mathrm{C}_{9}$-alkyl proton peaks at $\delta 0.4-2.1$ in intensity going from 5 to 7 with roughly similar multiplet peak patterns as those of the parent $\mathrm{BrF}-\mathrm{C}$ 9. Characteristics of the central benzene protons can be used for the analysis of the relative geometrically configuration of fluorenyl rings with respect to each other. In the case of mono(DPAF-C9) 5 (Figure 1c), two peaks centered at $\delta 6.33$ and 6.50 in a peak integration ratio of 2:1 were clearly detected that allowed us to assign them as the chemical shifts of $\mathrm{H}_{\mathrm{b}}$ and $\mathrm{H}_{\mathrm{c}}$, respectively, with the latter having a slight down-fielded shift of $0.18 \mathrm{ppm}$ from that of the singlet $\mathrm{H}_{\mathrm{c}}$ of 4 at $\delta 6.32$. As the number of fluorene addend $\left(\mathrm{F}-\mathrm{C}_{9}\right)$ increased to the structure of bis(DPAF-C9) 6, the central benzene protons changed to $\mathrm{H}_{\mathrm{a}}$ (fluorene rings at both sides, $1 \mathrm{H}$ ) and $\mathrm{H}_{\mathrm{b}}$ (one fluorene ring and one phenyl ring at either sides, 2H) types. Two peak groups located at $\delta 6.42$ (broad singlet) and 6.53 (singlet) in an integration ratio of 2:1 (Figure 1b) allowed a clear assignment 
to the chemical shift of $\mathrm{Hb}$ and $\mathrm{H}_{\mathrm{a}}$, respectively. The peak broadening and splitting at $\delta 6.42$ revealed two non-equivalent $\mathrm{Hbs}$, perhaps, as the result of a mixture of two possible geometrical conformational isomers of 6 with two fluorene rings either at a cis-conformation (up-up) or trans-conformation (up-down) since free rotation around the benzene-N bond is unlikely to occur. In addition, an increased complexity and number of fluorenyl proton peaks at $\delta 6.70-7.70$ also supported the existence of two non-equivalent geometrical conformers. Interestingly, the only major product of tris(DPAF-C9) 7 isolated showed full disappearance of $\mathrm{N}-\mathrm{H}_{\mathrm{d}}$ proton signal at $\delta 5.5-6.0$ and a singlet $\mathrm{H}_{\mathrm{a}}$ proton peak at $\delta 6.55$ (Figure 1a) in a similar chemical shift as that of $\mathrm{H}_{\mathrm{a}}$ in $\mathbf{6}$. The former indicated the completion of palladium-catalyzed amination reactions with three equivalents of light-harvesting DPAF-antenna moieties. The latter revealed three equivalent $\mathrm{H}_{\mathrm{a}}$ s that led us to suggest a cis-conformation (geometrically at the same side of the central benzene ring as up-up-up configuration for three fluorenyl rings) for the structure of 7 (more discussion below by structural simulation and calculation). Even though the peak and coupling pattern were more complex in the aromatic region of $\delta 7.0-8.0$ in the spectrum as compared to those of the precursor TPAB, however, without a symmetrical environment for three fluorenyl rings in the structure of 7, the number of aromatic proton peaks each with coupling multiplet should lead to a much more complicated spectrum than that of $\mathbf{6}$ in the same chemical shift region. Therefore, the observation of only a limit number of fluorenyl aryl proton peak groups at $\delta 6.82-7.57$ with an overall higher proton integration ratio to the peak of $\mathrm{H}_{\mathrm{a}}$ supported the argument of a quasi-symmetrical cis-conformation for 7.

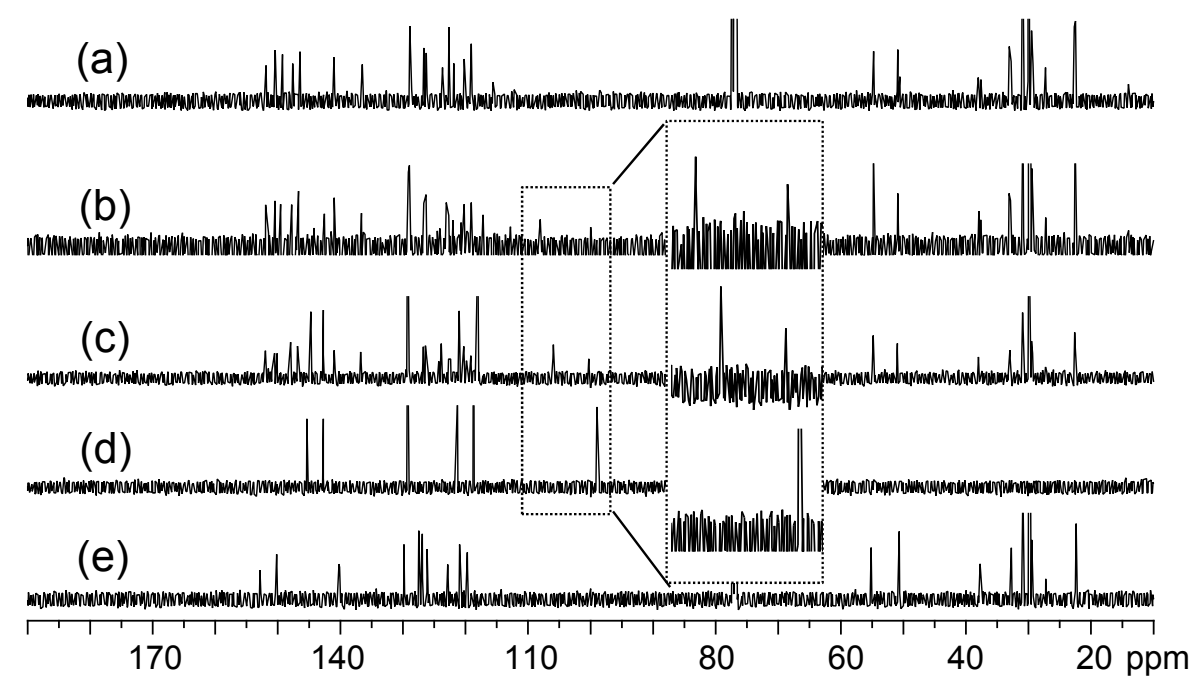

Figure 2. ${ }^{13} \mathrm{C}-\mathrm{NMR}$ spectra of (a) tris(DPAF-C9) 7, (b) bis(DPAF-C9) 6, (c) mono(DPAF-C9) 5, (d) TPAB 4, and (e) BrF-C9 2.

${ }^{13} \mathrm{C}$-NMR spectra of the precursor molecules TPAB were also used as the reference for the comparison with those of mono-, bis-, and tris(DPAF-C9). Attachment of one fluorenyl ring to TPAB led clearly to two sets of aromatic carbon $\left(\mathrm{sp}^{2}\right)$ peaks at $\delta 115-155$ in the ${ }^{13} \mathrm{C}-\mathrm{NMR}$ spectrum of 5 (Figure 2c). Chemical shifts of the group of five $\mathrm{sp}^{2}$ carbon peaks having higher peak intensity were roughly identical to those of TPAB (Figure 2d). This allowed us to assign the rest of multiple peaks in lower peak intensity to the fluorenyl carbons. The relative intensity of these two peak groups was found to increase progressively for the latter as the number of attached fluorenyl ring increased from $\mathbf{5}$, 
6 (Figure 2b), to 7 (Figure 2a), consistent with their corresponding structural composition. Upon the attachment of one DPAF-C9 to 4 , the central phenyl carbon $\left(\mathrm{C}_{c}\right)$ peak of TPAB at $\delta 99.0$ was found to split and shift down-field to $\delta 105.9\left(\mathrm{Cb}_{\mathrm{b}}\right)$ and $100.3\left(\mathrm{C}_{\mathrm{c}}\right)$, in an intensity ratio of roughly 2:1 consistent with the structure of 5, in Figure 2c of mono(DPAF-C9). Similar shifts to $\delta 108.0\left(\mathrm{C}_{\mathrm{a}}\right.$, Figure $\left.2 \mathrm{~b}\right)$ and $100.0\left(\mathrm{Cb}_{\mathrm{b}}\right)$ for bis(DPAF-C9) 6 and to $\delta 115.6\left(\mathrm{H}_{\mathrm{a}}\right.$, Figure $\left.2 \mathrm{a}\right)$ for tris(DPAF-C9) 7 were detected. These spectroscopic data provided an additional verification of the structures 5-7. High stability of 5-7 was observed during positive ion matrix-assisted laser desorption ionization (MALDI-TOF) mass spectroscopic measurements using 3,5-dimethoxy-4-hydroxycinnamic acid (sinapic acid) as the matrix, as shown in Figure 3a-c, respectively. All spectra of 5, 6, and 7 displayed a group of molecular ion mass $\left(\mathrm{MH}^{+}\right)$peaks at $m / z$ 768.9, 1184.9, and 1601.6 in good agreement with the calculated mass of $\mathrm{M}^{+}$ as $m / z 767.52,1183.86$, and 1600.21 , respectively. It also showed a clean fragmentation pattern consistent with a main fragmented ion mass peak at $\mathrm{m} / \mathrm{z} 510.2-510.5$, corresponding to the mass of $\mathrm{PhN}^{+} \mathrm{H}$-fluorene-C9. This revealed the central benzene- $\mathrm{N}$ bond as the weakest one to undergo dissociation. The data also provided unambiguous evidence of the successful synthesis of mono-, bis-, and tris(DPAF-C9).

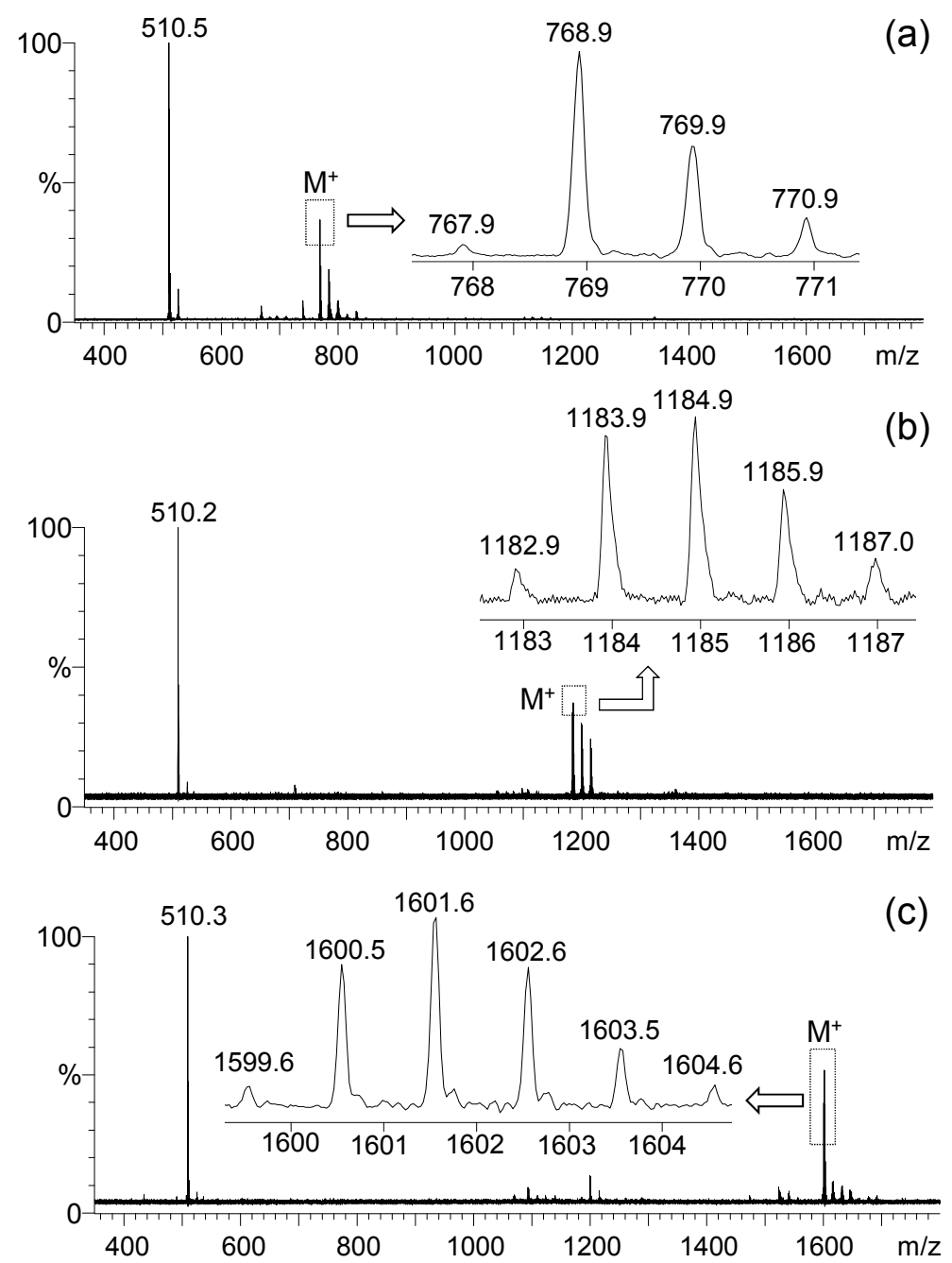

Figure 3. MALDI-TOF mass spectra of (a) mono(DPAF-C9) 5, (b) bis(DPAF-C9) 6, and (c) $\operatorname{tris}(\mathrm{DPAF}-\mathrm{C} 9) 7$. 
Effect of $\mathrm{TPAB}$ ratio with respect to $\mathrm{BrF}_{-} \mathrm{C}_{9}$ on the synthesis of tris(DPAF-C9) was also investigated. Our initial synthesis of tris(DPAF-C9) was carried out by using an exact three-equivalent amount of BrF-C9 in respect to the central TPAB core. It was found that this ratio of starting materials did not lead to a clean product, instead resulted in two different product fractions identified as bis- and tris(DPAF-C9) showing $\mathrm{H}_{\mathrm{a}}$ and $\mathrm{Hb}_{\mathrm{b}}$ proton peaks (supporting information) at $\delta 6.56$ and 6.48 , respectively, slightly down-field shifted in the mixture from those of the corresponding pure sample. By the integration ratio of these two peaks, the major product 7 and the minor product 6 were accounted for $69.0 \%$ and $31.0 \%$, respectively. Accordingly, we undertook the TPAB ratio-dependent evaluation of the production formation with three additional ratio of 1:2, 1:4, and 1:6 (excess). As a result, the decrease of TPAB quantity applied to $1: 2$, the $\mathrm{H}_{\mathrm{b}}$ peak intensity at $\delta 6.48$ increased significantly indicating the presence of mono(DPAF-C9) in addition to bis(DPAF-C9) as a mixture. Contrarily, the $\mathrm{Hb}$ peak decreased sharply in intensity, corresponding to the yield of 6 as $17.3 \%$, as the TPAB ratio being increased to $1: 4$. We found that a full reaction conversion to 7 became possible by using a TPAB ratio of $1: 6$, leading to the complete disappearance of $\mathrm{H}_{\mathrm{b}}$ peak in the product spectrum.

UV-vis spectra of TPAB 4, mono-5, and bis-6, and tris-7 collected at a concentration of $1.0 \times 10^{-5} \mathrm{M}$ in $\mathrm{CHCl}_{3}$ were shown in Figure 4A (solid lines). Chemical modification of TPAB with one or more fluorenyl moieties converted the secondary to corresponding tertiary amines that led to a gradual bathochromic shift from the absorption of 4 centered at $289 \mathrm{~nm}\left(\lambda_{\max }, \varepsilon=4.80 \times 10^{4} \mathrm{~L} \cdot \mathrm{mol}^{-1} \cdot \mathrm{cm}^{-1}\right)$ to that of 5 at $297 \mathrm{~nm}\left(\varepsilon=5.16 \times 10^{4}\right)$, of 6 at $308 \mathrm{~nm}\left(\varepsilon=5.56 \times 10^{4}\right)$, and of 7 at $323 \mathrm{~nm}$ $\left(\varepsilon=5.71 \times 10^{4} \mathrm{~L} \cdot \mathrm{mol}^{-1} \cdot \mathrm{cm}^{-1}\right)$. It also accompanied with a new band centered at $349 \mathrm{~nm}\left(\varepsilon=2.64 \times 10^{4}\right)$ for $5,348 \mathrm{~nm}\left(\varepsilon=5.07 \times 10^{4}\right)$ for $\mathbf{6}$, and $348 \mathrm{~nm}\left(\varepsilon=5.66 \times 10^{4} \mathrm{~L} \cdot \mathrm{mol}^{-1} \cdot \mathrm{cm}^{-1}\right)$ for 7 . Intensity of the latter band was found to increase progressively from 5 to 7 corresponding to the increasing number of fluorenyl moiety that allowed us to assign this peak to the characteristic absorption band of F-C9 moiety. With a new electron-releasing 3,5-diaminophenylamino group being bonded at $\mathrm{C}_{2}$ position of a F-C9, these bands presented a large bathochromic shift from those of BrF-C9 $\left(\lambda_{\max } 299\right.$ and $\left.310 \mathrm{~nm}\right)$ with an electron-withdrawing bromo group instead at the same carbon position. The shift also corresponds to an extended fluorenyl ring system interconnected by a 1,3,5-triaminobenzene central core, consistent with the structure of 5-7 synthesized.

All mono-5, and bis-6, and tris(DPAF-C9) are highly photoluminescent (PL) chromophores each showing an emission band at $\lambda_{\mathrm{em}, \max } 391.2,390.8$, and $390.1 \mathrm{~nm}$, respectively, (Figure 4A, dashed lines; $\lambda_{\mathrm{ex}}=360 \mathrm{~nm}$ ). Intensity of the band increased roughly in proportion to the number of $\mathrm{F}-\mathrm{C} 9$ rings substituted to TPAB. For the clarity, the absorption intensity and relative PL intensity of compounds 5-7 were normalized at the excitation wavelength of $360 \mathrm{~nm}$ as shown in Figure 4B. Partly owing to the molecular rigidity in the particular stereo-configuration with partial orbital overlap via unpaired electrons of amino groups at the center core of $\mathbf{7}$ as compared with those of $\mathbf{5}$ and $\mathbf{6}$, an obvious enhancement in the PL intensity (Figure 4B-a) was detected. Similar enhancement in a lesser extent was also observed in the bis(DPAF-C9) 6 (Figure 4B-b) in relation to that of mono(DPAF-C9) 5. This revealed emission-independency among $\mathrm{F}-\mathrm{C} 9$ units of 7 with no $\pi$-stacking related excimer or self-quenching effect, presumably, owing to the geometrical stereo-conformation of F-C9 moieties with respect to each other that prevented the close in-phase $\pi-\pi$ plane contact of fluorene rings and yielded high PL in significant intensity. Unlike tris(DPAF-C9), PL arising from the benzene and phenyl moieties of TPAB was fully quenched (Figure $4 \mathrm{~A}-\mathrm{d}$ at the baseline) providing evidence of strong 
intermolecular hydrogen bonding interactions between nitrogen and hydrogen among molecules, leading to a strong self-quenching effect. Accordingly, the $S_{0} \rightarrow S_{1}$ band gaps $(0,0)$ of 5, 6, and 7 can be estimated from the crossover onset position of their absorption and emission edges in $\mathrm{CHCl}_{3}$ and were found to be $3.24,3.26$ and $3.28 \mathrm{eV}$, respectively.
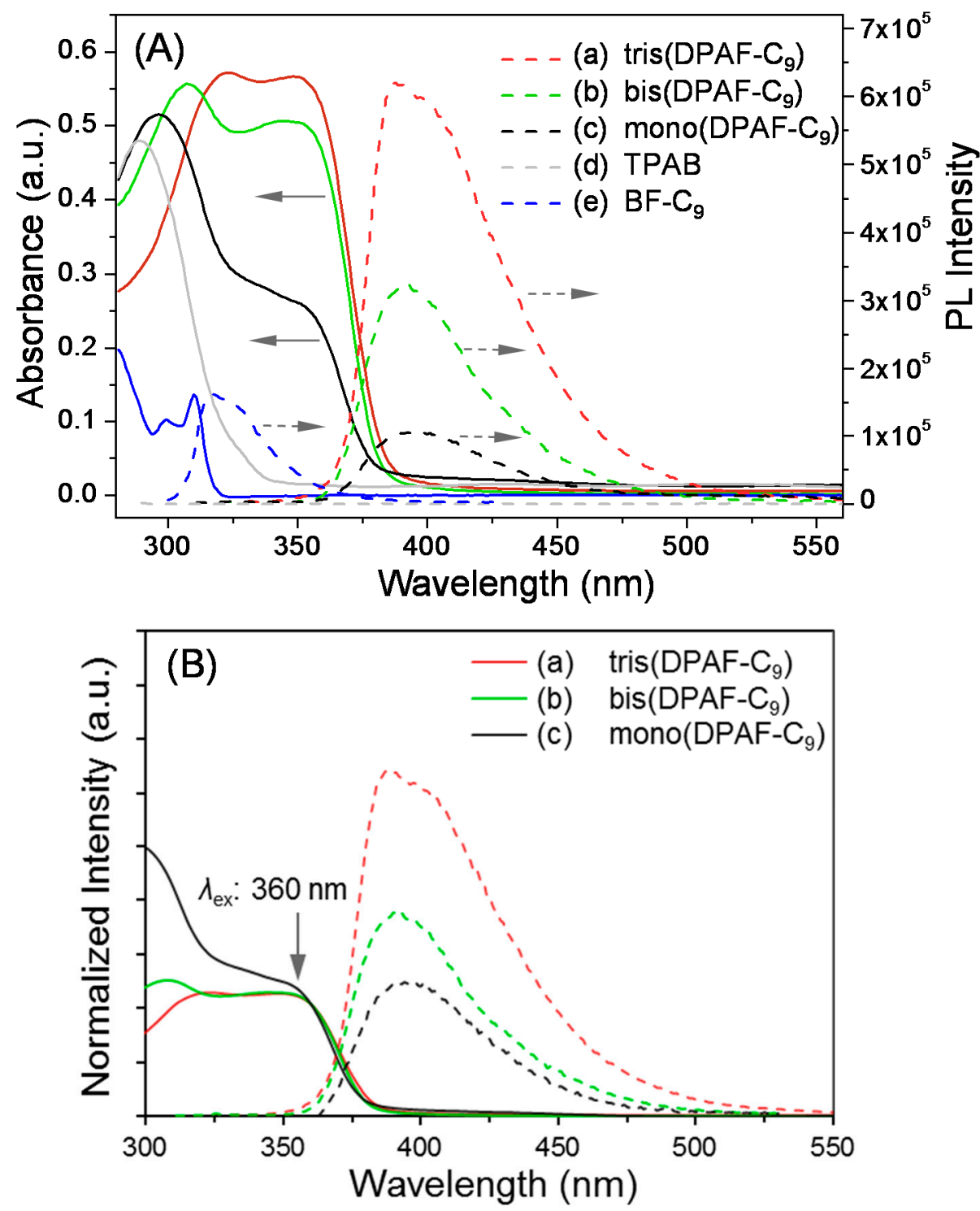

Figure 4. (A) UV-vis spectra (solid lines) and photoluminescence (dotted lines) of (a) tris(DPAF-C9) 7, (b) bis(DPAF-C9) 6, (c) mono(DPAF-C9) 5, (d) TPAB 4, and (e) BrF-C9 2 in $\mathrm{CHCl}_{3}$ at a concentration of $1.0 \times 10^{-5} \mathrm{M}$ and $(\mathbf{B})$ normalized absorption and PL intensity of 5-7 at the excitation wavelength of $360 \mathrm{~nm}$.

The fluorescent emission wavelength of $c i s$-tris(DPAF-C9) was found in a close range to that of PVK with both HOMO (-4.81 eV) and LUMO energy level $(-1.57 \mathrm{eV})$ in 1.0 and $0.7 \mathrm{eV}$, respectively, higher than those of PVK. The former is only slightly lower than that of $\operatorname{Ir}(\mathrm{ppy})_{3}$ $(-4.9 \mathrm{eV})$. Therefore, this donor chromophore may serve as the secondary blue hole-transporting material, which is capable of minimizing the aggregation-related self-quenching effect, in the modulation of PLED performance (supporting information Figure S5). 


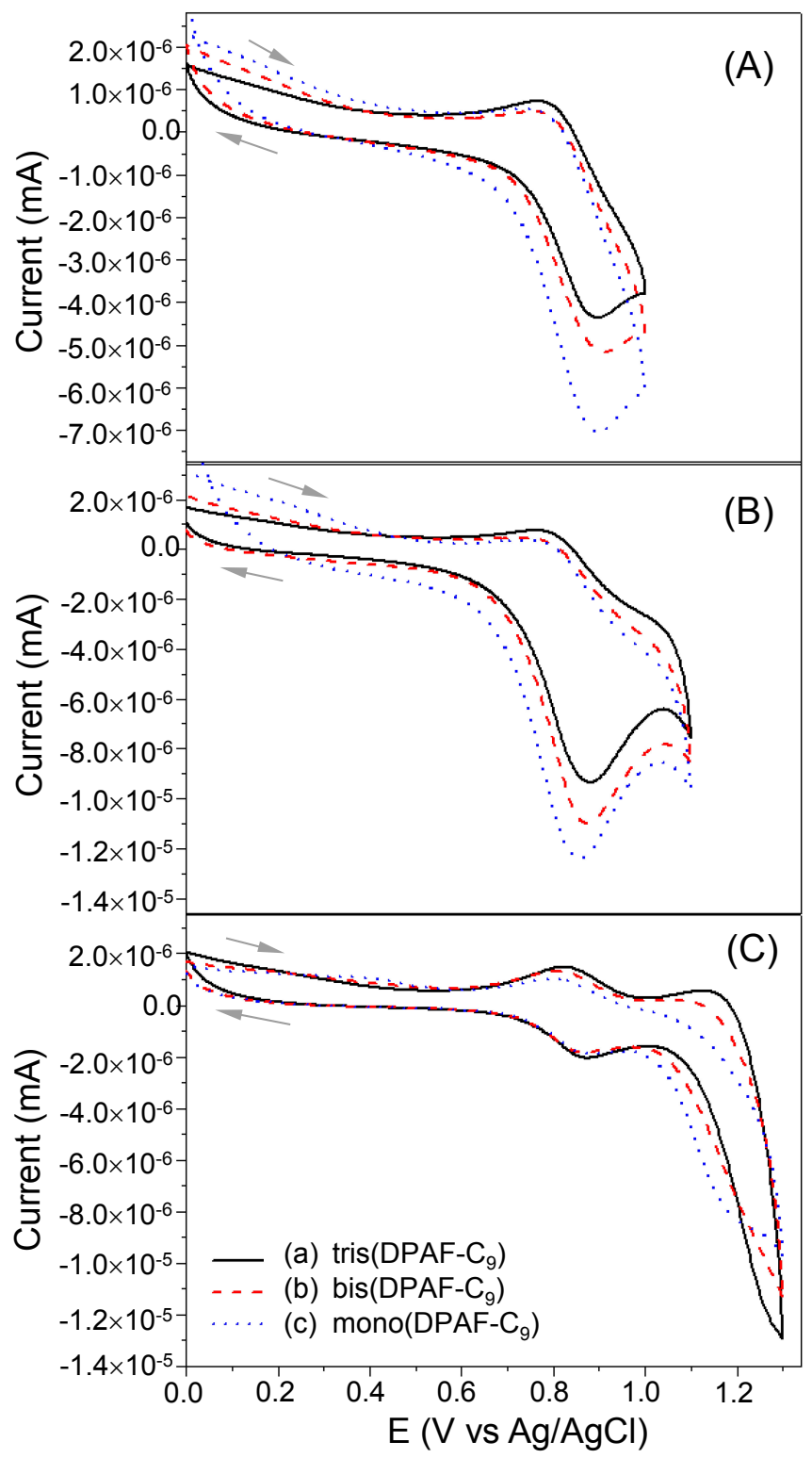

Figure 5. Cyclic voltammograms $(\mathrm{CV})$ of $(\mathbf{A}-\mathbf{C})$ at different voltages vs $\mathrm{Ag} / \mathrm{AgCl}$ with (a) tris(DPAF-C9) 7, (b) bis(DPAF-C9) 6, and (c) mono(DPAF-C9) 5 solution in a concentration of $1.75 \times 10^{-3} \mathrm{M}$ in $\mathrm{CH}_{3} \mathrm{CN}-\mathrm{CH}_{2} \mathrm{Cl}_{2}$, containing (n-butyl) ${ }_{4} \mathrm{~N}^{+}-\mathrm{PF}_{6}^{-}$ electrolyte $(0.4 \mathrm{M})$, using $\mathrm{Pt}$ as working and counter electrodes and $\mathrm{Ag} / \mathrm{AgCl}$ as the reference electrode at a scan rate of $10 \mathrm{mV} / \mathrm{s}$.

We also carried out the cyclic voltammetry (CV) measurement of mono-5, bis-6, and tris-7 in a solvent mixture of $\mathrm{CH}_{2} \mathrm{Cl}_{2}-\mathrm{CH}_{3} \mathrm{CN}$ in the presence of (n-butyl) ${ }_{4} \mathrm{~N}^{+}-\mathrm{PF}_{6}{ }^{-}$electrolyte, using $\mathrm{Pt}$ as working and counter electrodes and $\mathrm{Ag} / \mathrm{AgCl}$ as the reference electrode. The $\mathrm{CV}$ characteristics of compounds 5-7 under variation of the cyclic oxidation voltage vs $\mathrm{Ag} / \mathrm{AgCl}$ from 1.0 to $1.3 \mathrm{~V}$ were evaluated, as shown in Figure 5A-C. As a result, only one consistent reversible redox wave was detectable in a similar current range $(0.0-1.1 \mathrm{~V})$ for all three compounds indicating that only one F-C9 ring moiety was participating the oxidation-reduction cycle at the same concentration regardless its structure being mono-, bis-, or tris-adduct of TPAB. This revealed full electrochemical independency of all $\mathrm{F}-\mathrm{C}_{9}$ rings in the structure. By taking the most stable (symmetrical) and reversible first cyclic 
wave of Figure $5 \mathrm{C}$ as an example, a nearly identical onset oxidation potential ( $\left.E_{\text {ox }}{ }^{\text {onset }}\right)$ was measured for 5, 6, and 7 as $0.83 \mathrm{~V}$. Under the same $\mathrm{CV}$ conditions, the first half-wave redox potential of ferrocence reference sample was measured as $0.82 \mathrm{~V}$. Therefore, by taking the oxidation potential value of ferrocence at $-4.8 \mathrm{eV}$ below the vacuum level as the reference, the HOMO levels of mono-5, bis-6, and tris-7 were calculated as a nearly identical value of $-4.81 \mathrm{eV}$ that was summarized in Table 1. Furthermore, the optical energy gap $\left(E_{\mathrm{opt}}, \mathrm{S}_{0} \rightarrow \mathrm{S}_{1}\right.$ band gap) can be obtained and calculated from the absorption onset of all compounds 5, 6, and 7, via Figure 4, in a value of 3.28, 3.26, and $3.24 \mathrm{eV}$, respectively, as discussed above. Consequently, corresponding LUMO levels were then calculated as $-1.53,-1.55$, and $-1.57 \mathrm{eV}$, respectively.

Table 1. Electrochemical properties of mono-5, bis-6, and tris(DPAF-C9) 7.

\begin{tabular}{|c|c|c|c|c|}
\hline Compound & $E_{\text {ox }}{ }^{\text {onset }}(\mathrm{V})$ & HOMO (eV) ${ }^{a}$ & $E_{\text {opt }}(\mathrm{eV})^{b}$ & LUMO (eV) \\
\hline Tris(DPAF-C 9 ) 7 & 0.83 & -4.81 & 3.24 & -1.57 \\
\hline $\operatorname{Bis}\left(\mathrm{DPAF}_{-} \mathrm{C}_{9}\right) 6$ & 0.83 & -4.81 & 3.26 & -1.55 \\
\hline Mono(DPAF-C 9 ) 5 & 0.83 & -4.81 & 3.28 & -1.53 \\
\hline
\end{tabular}

${ }^{a}$ Estimated from the onset oxidation potential; ${ }^{b}$ Estimated from the onset of absorption edge.

In the consideration of the structural configuration, it is reasonable to expect two possible nonplanar geometrical stereoisomers as, namely, tris-trans- (with two fluorenyl rings at the same side of the central benzene ring and one fluorenyl rings located at the opposite side as an up-up-down configuration) and tris-cis-conformation (geometrically at the same side of the central benzene ring as an up-up-up configuration for all three fluorenyl rings) analogues, for the structure of tris(DPAF-C9) 7 in spite of only one chromatographic spot being detected on TLC (silica gel, toluene-hexane, 5:95). This observation clearly suggests that the 3D-structure of 7 may not be a planar configuration with the fluorenyl and/or the phenyl rings being possibly twisted relative to the center core position, forming a pair of cis/trans stereo-conformers or isolable isomers, as discussed in Figure 6. In order to estimate the $\mathrm{C}-\mathrm{C}$ bond rotational barrier energy of tris(DPAF-C 9 ) between possible stereo-conformers, we conducted the variable temperature NMR measurement in the range of 300-335 $\mathrm{K}$ in $\mathrm{CDCl}_{3}$. However, we did not observe any clear difference except small peak broadening. This result suggested that the rotational barrier energy is high enough to restrict the cis-trans isomerization and allowed the isolation of a single isomer at least in room temperature.

As we described above, uncongested ${ }^{1} \mathrm{H}-\mathrm{NMR}$ spectrum of tris(DPAF-C9) 7 revealed a $\mathrm{C}_{3}$-symmetrical cis-conformation for its structure. Our puzzle existed regarding to the exclusive formation of, supposedly, sterically unfavorable cis-isomer. Accordingly, we undertook the comparison of formation energy by calculation on the 3D-structure of three plausible isomers of tris(DPAF-C9) 7, as shown in Figure 6. Two cis-forms, especially a cis-(cup-)form, seem to be more crowded than trans-(chair-)form. Surprisingly, heat of formation $\left(\Delta H_{\mathrm{f}}\right)$ calculated by the semi-empirical PM3 method revealed unexpectedly high stability of the cup-form with other forms in an order of chair $\approx$ cup $>$ propeller for C9 substituents $(-9.19,-9.13$, and $-4.40 \mathrm{kcal} / \mathrm{mol}$, respectively) and the highest stability of cup-forms (cup > chair > propeller) for the slightly less crowded $n-\mathrm{C}_{6}, \mathrm{C}_{7}$, and $\mathrm{C}_{8}$ substituents. Such cup-form formation tends to be more preferable as the alkyl chains at 9-fluorenyl position become longer as can be seen in the differential heat of formation $\Delta \Delta H_{\mathrm{f}}$ for both cup-propeller and cup-chair energy gaps 
(Table 2). These results imply that hydrophobic interaction between three alkyl chains as well as $\mathrm{CH} / \pi$ interaction between the alkyl group and the fluorenyl ring plays an important role for the preferential formation of the cup-form. The DFT calculation at B3LYP/6-31G* level of theory for some alkyl groups resulted in the similar tendency, although the values suggested the slightly more stable chair-form even for $n-\mathrm{C}_{6}$ group as compared with the cup-form, probably due to the lack of consideration on the solvent polarity which affects to hydrophobic interactions (Table 3).

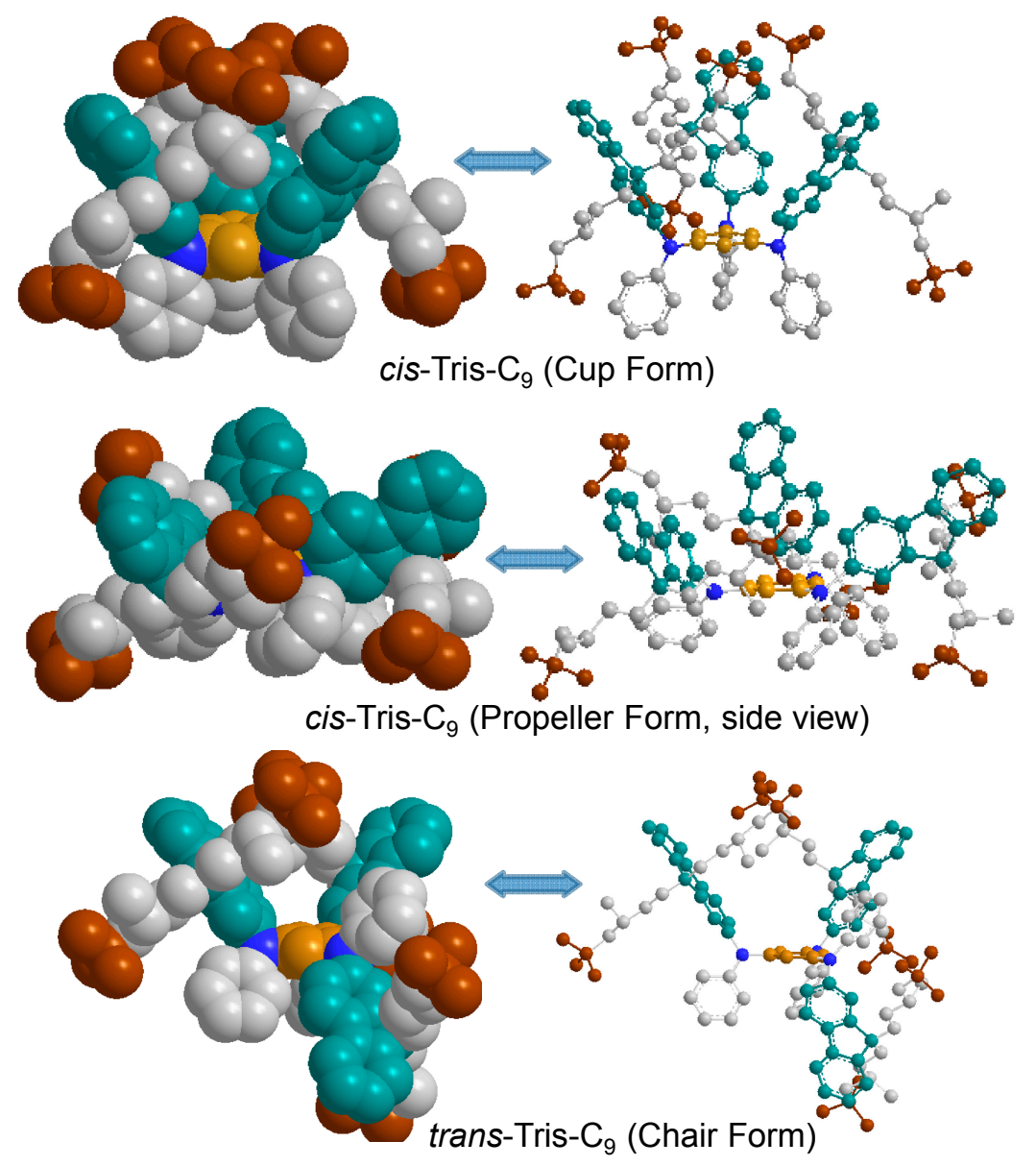

Figure 6. Optimized geometrical structures of tris(DPAF-C9) 7, by calculation, showing a different degree of interaction force among terminal $t$-butyl groups (brown).

Table 2. Calculated heat of formation for tris(DPAF-C $)^{a}{ }^{a}$

\begin{tabular}{|c|c|c|c|c|c|}
\hline \multirow{3}{*}{$\begin{array}{l}R^{b} \\
\left(C_{n}\right)\end{array}$} & \multicolumn{3}{|c|}{$\Delta H_{\mathrm{f}}(\mathrm{kcal} / \mathrm{mol})$} & \multicolumn{2}{|c|}{$\Delta \Delta H_{\mathrm{f}}(\mathrm{kcal} / \mathrm{mol})$} \\
\hline & \multicolumn{2}{|c|}{ cis } & \multirow{2}{*}{$\begin{array}{l}\text { trans } \\
\text { chair }\end{array}$} & \multirow[t]{2}{*}{ cup-propeller } & \multirow{2}{*}{$\begin{array}{l}\text { cup-chair } \\
\text { (cis-trans) }\end{array}$} \\
\hline & cup & propeller & & & \\
\hline $\mathrm{Me}$ & 258.38 & 253.67 & 247.85 & 4.71 & 10.53 \\
\hline Et & 231.59 & 223.91 & 233.48 & 7.68 & 1.89 \\
\hline$n-\mathrm{C}_{6}$ & 87.01 & 95.12 & 93.67 & -8.11 & -6.66 \\
\hline $\mathrm{C}_{7}$ & 59.59 & 64.00 & 60.07 & -4.41 & -0.48 \\
\hline $\mathrm{C}_{8}$ & 22.23 & 28.10 & 22.52 & -5.87 & -0.29 \\
\hline $\mathrm{C}_{9}$ & -9.13 & -4.40 & -9.19 & -4.73 & 0.06 \\
\hline
\end{tabular}

${ }^{a}$ Calculated by semi-empirical PM3 method using Spartan 08. ${ }^{b}$ Substituents at 9-fluorenyl position. $\mathrm{C}_{7}$ : 3-methylhexyl group (3-Me); $\mathrm{C}_{8}$ : 5,5-dimethylhexyl group (4-t-Bu); $\mathrm{C}_{9}$ : 3,5,5-trimethylhexyl group (3-Me-4-t-Bu). 
Table 3. DFT calculation of heat of formation for tris(DPAF-C $)^{a}$.

\begin{tabular}{cccc}
\hline $\mathbf{R}^{\boldsymbol{b}}$ & \multicolumn{2}{c}{$\boldsymbol{\Delta \boldsymbol { H } _ { \mathbf { f } } ( \mathbf { k c a l } / \mathbf { m o l } )}$} & $\boldsymbol{\Delta} \boldsymbol{\Delta} \boldsymbol{H}_{\mathbf{f}}(\mathbf{k c a l} / \mathbf{m o l})$ \\
\cline { 2 - 3 }$\left(\mathbf{C}_{\mathbf{n}}\right)$ & cis $($ cup $)$ & trans $($ chair $)$ & cup-chair \\
\hline $\mathrm{Et}$ & -1922585.7 & -1922609.1 & 23.4 \\
$\mathrm{MeOC}_{2} \mathrm{H}_{4}$ & -2353750.4 & -2353762.0 & 11.6 \\
$n-\mathrm{C}_{6}$ & -2514673.7 & -2514677.3 & 3.6 \\
$\mathrm{C}_{9}$ & -2958697.2 & -2958703.8 & 6.6 \\
\hline
\end{tabular}

${ }^{a}$ Calculated at B3LYP/6-31G* level of theory using SPARTAN08. ${ }^{b}$ Substituents at 9-fluorenyl position.

The unexpected stability of cup-form may be explained by the torsional angle of the center benzene ring defined by the position of aryl groups on nitrogen atoms. The calculated torsional (dihedral) angles between the aryl-nitrogen $\mathrm{C}-\mathrm{N}$ bond and the center benzene ring $\mathrm{C}-\mathrm{C}$ bond for two cis-conformers of tris(DPAF-C9) (cup-form and propeller-form) obtained from the optimized 3D-structure are illustrated in Figure 7. The angle strain of the cup-form was found to be much less than that of the propeller-form. The angle strain of trans-conformers is somewhat higher than that of the symmetrical cup-form due to unavoidable unsymmetrical conformation of the chair-form. Therefore, the highly symmetrical cis-cup-isomer of tris(DPAF-C9) can be formed exclusively.

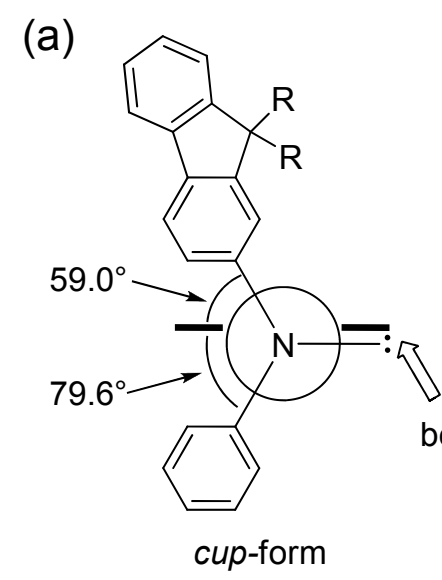

(b)

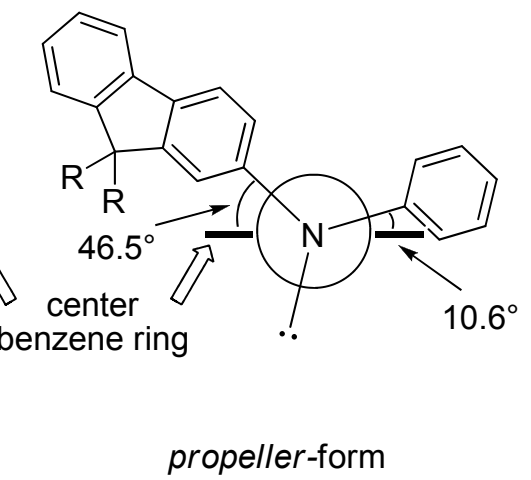

Figure 7. Torsional (dihedral) angles between aryl-nitrogen bond and center benzene ring for (a) cup-form and (b) propeller-form of tris(DPAF-C9) 7.

In summary, above explanations for the preferential cis-cup-formation are supported by results of the calculated heat of formation and dihedral angle, which are based on the thermodynamically controlled mechanism. However, the restricted bond rotation may not give the thermodynamically stable isomer under the present condition. Therefore, an alternative explanation for the preferential cis-cup-formation of tris(DPAF-C9) is also considered based on the kinetically controlled mechanism in the critical amination reaction. Fluorenyl substitution at three phenylamino groups on the central benzene ring of TPAB occurs one by one to form mono(DPAF-C9), bis(DPAF-C9), and tris(DPAF-C9) sequentially. Owing to the unrestricted rotation of phenylamino group, two phenyl groups on nitrogen atoms can be escaped from a larger fluorenyl substituent group via the steric hindrance. Consequently, the tendency of subsequent substitution of a second fluorenyl group should favor the formation of cis-bis(DPAF-C9). This preferred configuration may hinder its isomerization to the trans-form due to 
the restricted bond rotation. Similarly, the third substitution of the last fluorenyl group should lead to the selective product of $c i$ s-tris(DPAF-C9) (supporting information).

\section{Experimental}

Materials. Reagents and solvent of 3,5,5-trimethylhexanol, methanesulfonyl chloride, triethylamine, 2-bromofluorene, 1,3,5-tribromobenzene, rac-2,2'-bis(diphenylphosphino)-1,1'-binaphthyl (rac-BINAP), tris(dibenzylideneacetone)dipalladium $(0)\left[\mathrm{Pd}_{2}(\mathrm{dba})_{3}(0)\right]$, aniline, and dichloroethane were purchased from Aldrich Chemicals (Milwaukee, WI, USA) and used without further purification. All other chemicals were purchased from Acros Ltd. (Fair Lawn, NJ, USA). The anhydrous grade solvent of THF was refluxed over sodium and benzophenone overnight and distilled under reduced pressure $\left(10^{-1} \mathrm{mmHg}\right)$.

Spectroscopic Measurements. ${ }^{1} \mathrm{H}-\mathrm{NMR}$ and ${ }^{13} \mathrm{C}-\mathrm{NMR}$ spectra were recorded on either a Bruker Avance Spectrospin-200 or Bruker AC-300 spectrometer (Bruker, Billerica, MA, USA). UV-vis spectra were recorded on a U-3410 UV spectrometer (Hitachi, Schaumburg, IL, USA). Infrared spectra were recorded as $\mathrm{KBr}$ pellets on a Nicolet 750 series FT-IR spectrometer (Thermo Electron Corporation, Madison, WI, USA). Photoluminescence (PL) spectra were measured using a PTI (Birmingham, NJ, USA) Fluorescence Master Systems connected with a photomultiplier (914 Photomultiplier Detection System), with a xenon short arc lamp as the excitation source. Mass spectroscopic measurements were performed by the use of positive ion matrix-assisted laser desorption ionization (MALDI-TOF) technique on a micromass M@LDI-LR mass spectrometer (Bruker, Billerica, MA, USA). The sample blended or dissolved in the matrix material was irradiated by nitrogen UV laser at $337 \mathrm{~nm}$ with $10 \mathrm{~Hz}$ pulses under high vacuum. Mass ion peaks were identified for the spectrum using the MassLynx v4.0 software. In a typical experiment, the samples of 5, 6, and 7, were dissolved in $\mathrm{CHCl}_{3}$ in a concentration of $1.0 \mathrm{mg} / \mathrm{mL}$. The matrix of 3,5-dimethoxy-4-hydroxycinnamic acid (sinapic acid) was dissolved in THF in a concentration of $10 \mathrm{mg} / \mathrm{mL}$. The solution of matrix $(1.0 \mathrm{~mL})$ was taken and mixed with the sample solution $(0.1 \mathrm{~mL})$ prior to the deposition on a stainless-steel MALDI target probe. It was subsequently dried at ambient temperature.

\section{Synthetic Procedures}

Synthesis of 3,5,5-Trimethylhexyl Methanesulfonate

To a stirred solution of 3,5,5-trimethylhexanol $(5.0 \mathrm{~g}, 34.6 \mathrm{mmol})$ in anhydrous dichloroethane $(75 \mathrm{~mL})$ was added triethylamine $(3.85 \mathrm{~g}, 38.12 \mathrm{mmol})$. This reaction mixture was cooled to $0{ }^{\circ} \mathrm{C}$ in ice bath, follwed by dropwise addition of methane sulfonyl chloride (4.36 g, $38.12 \mathrm{mmol}$ ) over a period of $15 \mathrm{~min}$ under nitrogen. The reaction mixture was stirred for overnight and quenched by the addition of water. Organic layer was washed with water $(2 \times 50 \mathrm{~mL})$, dil. hydrochloric acid $(1 \times 50 \mathrm{~mL})$, saturated sodium bicarbonate $(1 \times 50 \mathrm{~mL})$, and brine solution $(1 \times 50 \mathrm{~mL})$. The residue was dried over sodium sulphate and concentrated on a rotavapor to afford crude light brown colored liquid. After chromatographic purification, the product 3,5,5-trimethylhexyl methanesulfonate was obtained in a yield of $95 \%$, as a colorless liquid after vacuum distillation at $130-140{ }^{\circ} \mathrm{C} .{ }^{1} \mathrm{H}-\mathrm{NMR}\left(500 \mathrm{MHz}, \mathrm{CDCl}_{3}\right) \delta 4.25$ $(\mathrm{t}, J=6.8 \mathrm{~Hz}, 2 \mathrm{H}), 3.01(\mathrm{~s}, 3 \mathrm{H}), 1.77$ (dq, $J=13.8,6.9,6.4 \mathrm{~Hz}, 1 \mathrm{H}), 1.67$ (q, $J=8.0,6.3 \mathrm{~Hz}, 1 \mathrm{H}), 1.57$ 
$(\mathrm{dq}, J=13.3,6.6 \mathrm{~Hz}, 1 \mathrm{H}), 1.24-1.20(\mathrm{~m}, 1 \mathrm{H}), 1.14-1.10(\mathrm{~m}, 1 \mathrm{H}), 0.97(\mathrm{~d}, J=6.6 \mathrm{~Hz}, 3 \mathrm{H}), 0.90$ (s, $8 \mathrm{H})$, and $0.87-0.76(\mathrm{~m}, 1 \mathrm{H})$.

Synthesis of 2-Bromo-9,9-bis(3',5',5'-trimethyl-1'-hexyl)fluorene (BrF-C9, 2)

To a solution of 2-bromofluorene $1(5.0 \mathrm{~g}, 20.4 \mathrm{mmol})$ in anhydrous tetrahydrofuran $(100 \mathrm{~mL})$ was added potassium $t$-butoxide $(5.03 \mathrm{~g}, 44.80 \mathrm{mmol})$ at $0{ }^{\circ} \mathrm{C}$. The resulting orange brown colored reaction mixture was stirred for $30 \mathrm{~min}$. To this reaction mixture 3,5,5-trimethylhexyl methanesulfonate $(9.98 \mathrm{~g}$, $44.8 \mathrm{mmol})$ in anhydrous tetrahydrofuran $(25 \mathrm{~mL})$ was added dropwise over a period of $30 \mathrm{~min}$. It was stirred for overnight and subsequently diluted with water $(50 \mathrm{~mL})$. The product was extracted with ethyl acetate $(150 \mathrm{~mL})$, washed with water, and dried over anhydrous sodium sulfate $\left(\mathrm{Na}_{2} \mathrm{SO}_{4}\right)$. The pale yellow crude product was purified by column chromatography using silica gel as the stationary phase and hexane-ethyl acetate $(19: 1)$ as the eluent. The purified product 2-bromo-9,9-bis(3',5',5'trimethyl-1'-hexyl)fluorene 2, BrF-C9, was obtained as colorless liquid in 90\% yield (9.1 g). FT-IR (KBr) $v_{\max } 3063(\mathrm{~m}), 3024(\mathrm{~m}), 2953$ (s), $2868(\mathrm{~s}), 2744(\mathrm{w}), 2,715(\mathrm{w}), 1944(\mathrm{w}), 1905(\mathrm{w}), 1875(\mathrm{w})$, 1799 (w), 1749 (w), 1,642 (w), 1599 (m), 1570 (m), 1466 (s), 1443 (s), 1406 (m), 1389 (m), 1364 (s), $1292(\mathrm{w}), 1264(\mathrm{~m}), 1246(\mathrm{~m}), 1217(\mathrm{~m}), 1155(\mathrm{w}), 1132(\mathrm{w}), 1062(\mathrm{~m}), 1028(\mathrm{w}), 1005(\mathrm{~m}), 972(\mathrm{w})$, $935(\mathrm{w}), 877(\mathrm{~m}), 822(\mathrm{~m}), 781(\mathrm{~m}), 758(\mathrm{~m}), 736(\mathrm{~s}), 643(\mathrm{w})$, and $572(\mathrm{~m}) \mathrm{cm}^{-1}$; UV-vis $\left(\mathrm{CHCl}_{3}\right.$, $\left.1.0 \times 10^{-5} \mathrm{M}\right) \lambda_{\max }(\varepsilon) 279\left(2.04 \times 10^{4}\right), 299\left(1.03 \times 10^{4}\right)$, and $310 \mathrm{~nm}\left(1.37 \times 10^{4} \mathrm{~L} \mathrm{~mol}^{-1} \mathrm{~cm}^{-1}\right)$; ${ }^{1} \mathrm{H}-\mathrm{NMR}\left(500 \mathrm{MHz}, \mathrm{CDCl}_{3}\right) \delta$ 7.70-7.62 (m, 1H), $7.54(\mathrm{~d}, J=7.9 \mathrm{~Hz}, 1 \mathrm{H}), 7.45-7.43(\mathrm{~m}, 2 \mathrm{H}), 7.31(\mathrm{~s}$, $3 \mathrm{H}), 2.02-1.87(\mathrm{~m}, 4 \mathrm{H}), 1.22-1.13(\mathrm{br}, 2 \mathrm{H}), 0.96-0.95(\mathrm{~m}, 1 \mathrm{H}), 0.93-0.92(\mathrm{~m}, 1 \mathrm{H}), 0.84-0.77$ (m, $3 \mathrm{H}), 0.73(\mathrm{t}, J=5.3 \mathrm{~Hz}, 23 \mathrm{H}), 0.58-0.50(\mathrm{~m}, 2 \mathrm{H})$, and $0.47-0.39(\mathrm{~m}, 2 \mathrm{H}) ;{ }^{13} \mathrm{C}-\mathrm{NMR}(125 \mathrm{MHz}$, $\left.\mathrm{CDCl}_{3}\right) \delta 152.9,150.2,140.2,140.1,129.8,127.5,126.9,126.1,122.8,121.0,120.9,119.7,55.2$, $50.74,50.65,37.82,37.79,37.7,32.81,32.75,30.9,29.9,29.5,29.4,22.5$, and 22.4.

Synthesis of 1,3,5-Tris(phenylamino)benzene (TPAB, 4)

A mixture of aniline (7.4 g, $79.4 \mathrm{mmol})$, 1,3,5-tribromobenzene 3 (5.0 g, $15.88 \mathrm{mmol})$, tris(dibenzylideneacetone) dipalladium $(0) \quad\left[\mathrm{Pd}_{2}(\mathrm{dba})_{3}(0), \quad 0.11 \quad \mathrm{~g}, \quad 0.25 \mathrm{~mol} \%\right], \quad$ rac-2,2'bis(diphenylphosphino)-1,1'-binapthyl (BINAP, $0.22 \mathrm{~g}, 0.75 \mathrm{~mol} \%$ ), and sodium $t$-butoxide (7.63 g, $79.4 \mathrm{mmol})$ in anhydrous toluene $(250 \mathrm{~mL})$ was heated to refluxing temperature under nitrogen for a period of $72 \mathrm{~h}$. The reaction mixture was cooled to room temperature and washed with water $(100 \mathrm{~mL})$. The organic layer was dried over anhydrous sodium sulfate $\left(\mathrm{Na}_{2} \mathrm{SO}_{4}\right)$. After evaporation of the solvent, a crude brown color solid was obtained. Excess aniline was then removed by distillation at $130{ }^{\circ} \mathrm{C}$ under reduced pressure of $10^{-1} \mathrm{mmHg}$. It was further purified by chromatography $\left(\mathrm{SiO}_{2}\right)$. The resulting light brown product 1,3,5-tris(phenylamino)benzene 4, TPAB, was obtained in 75\% yield (4.18 g). FT-IR (KBr) $v_{\max } 3403(\mathrm{~m}), 3375(\mathrm{~m}), 3078(\mathrm{w}), 3019(\mathrm{w}), 2945$ (s), 1612 (m), 1591 (vs), 1518 (m), 1496 (s), 1469 (m), 1431(w), 1456 (m), 1409 (m), 1365 (w), 1295 (m), 1269 (w), 1246 (m), 1,171 (m), $1073(\mathrm{w}), 1030(\mathrm{w}), 897(\mathrm{w}), 834(\mathrm{w}), 820(\mathrm{w}), 802(\mathrm{w}), 756(\mathrm{~m}), 721(\mathrm{w}), 700(\mathrm{~m}), 688(\mathrm{~m}), 613(\mathrm{w})$, and $558(\mathrm{w}) \mathrm{cm}^{-1}$; UV-vis $\left(\mathrm{CHCl}_{3}, 1.0 \times 10^{-5} \mathrm{M}\right) \lambda_{\max }(\varepsilon) 289 \mathrm{~nm}\left(4.80 \times 10^{4} \mathrm{~L} \mathrm{~mol}^{-1} \mathrm{~cm}^{-1}\right) ;{ }^{1} \mathrm{H}-\mathrm{NMR}$ $\left(500 \mathrm{MHz}, \mathrm{CDCl}_{3}\right) \delta 7.25(\mathrm{t}, J=7.8 \mathrm{~Hz}, 6 \mathrm{H}), 7.08(\mathrm{~d}, J=7.7 \mathrm{~Hz}, 6 \mathrm{H}), 6.92(\mathrm{t}, J=7.3 \mathrm{~Hz}, 3 \mathrm{H}), 6.32$ (s, $3 \mathrm{H})$, and $5.60(\mathrm{~s}, 3 \mathrm{H}, \mathrm{N}-\mathrm{H})$; ${ }^{13} \mathrm{C}-\mathrm{NMR}\left(125 \mathrm{MHz}, \mathrm{CDCl}_{3}\right) \delta 145.4,142.7,129.3,121.3,118.7$, and 99.0 . 
Synthesis of $N^{1}, N^{3}, N^{5}$-Tris(9,9-di(3',5',5'-trimethyl-1'-hexyl)fluoren-2-yl)-1",3",5"-tris(phenylamino)benzene [tris(DPAF-C9), 7]

A mixture of 2-bromo-9,9-bis(3',5',5'-trimethyl-1'-hexyl)fluorene (8.39 g, $17.04 \mathrm{mmol}$, excess), 1,3,5-tris $(N$-phenylamino)benzene (1.0 g, $2.84 \mathrm{mmol})$, tris(dibenzylideneacetone)dipalladium( $(0)$ $\left[\mathrm{Pd}_{2}(\mathrm{dba})_{3}(0), 0.02 \mathrm{~g}, 0.25 \mathrm{~mol} \%\right], r a c-2,2^{\prime}$-bis(diphenylphosphino)-1,1'-binapthyl (BINAP, $0.04 \mathrm{~g}$, $0.75 \mathrm{~mol} \%$ ), and sodium $t$-butoxide $(1.63 \mathrm{~g}, 17.04 \mathrm{mmol})$ in anhydrous toluene $(75 \mathrm{~mL})$ was heated to refluxing temperature under nitrogen for a period of $72 \mathrm{~h}$. The reaction mixture was cooled to room temperature and washed with water $(50 \mathrm{~mL})$. The organic layer was dried over anhydrous sodium sulfate. After evaporation of the solvent, it afforded a crude brown colored paste. The paste was subjected to column chromatography purification using silica gel as the stationary phase and hexane-ethylacetate (9:1) as the eluent, to afford $N^{1}, N^{3}, N^{5}$-tris(9,9-di(3',5',5'-trimethyl-1'-hexyl)fluoren-2-yl)-1",3",5"tris(phenylamino)-benzene, tris(DPAF-C9) 7, as light yellow solids or clear thick sticky gel-like paste, while residual solvents are present, in $88 \%$ yield $(3.98 \mathrm{~g}$ ). FT-IR (KBr) vmax 3,063 (w, aromatic C-H stretching), 3,037 (w), 3,019 (w), 2,953 (vs, aliphatic C-H stretching), 2,865 (s), 1,583 (s, C=C), 1500 (s), 1,493 (s, anti-symmetric deformations of $\mathrm{CH}_{3}$ groups and scissor vibrations of $\mathrm{CH}_{2}$ groups), 1,450, 1392 (w), 1363 (m, symmetric deformations of $\mathrm{CH}_{3}$ groups), 1294 (m, asymmetric stretching vibrations of C-N-C), 1249 (w, asymmetric stretching vibrations of C-N-C), 1212 (w), 1178 (w), 1155 (w), 1037 (w), 1006 (w), 933 (w), 878 (w), 826 (w), 756 (w), 738 (s, C-H out-of-plan deformation), 711 (m, C-H out-of-plan deformation), $693(\mathrm{~m}), 628(\mathrm{w})$, and $510(\mathrm{w}) \mathrm{cm}^{-1}$; UV-vis $\left(\mathrm{CHCl}_{3}, 1.0 \times 10^{-5} \mathrm{M}\right) \lambda_{\max }(\varepsilon) 323\left(5.71 \times 10^{4}\right)$ and $348 \mathrm{~nm}\left(5.66 \times 10^{4} \mathrm{~L} \mathrm{~mol}^{-1} \mathrm{~cm}^{-1}\right) ; \mathrm{PL}\left(\mathrm{CHCl}_{3}\right.$, $\left.1.0 \times 10^{-5} \mathrm{M}\right) \lambda_{e m, \max } 390.1 \mathrm{~nm} ;{ }^{1} \mathrm{H}-\mathrm{NMR}\left(500 \mathrm{MHz}, \mathrm{CDCl}_{3}\right) \delta 7.57(\mathrm{~s}, 3 \mathrm{H}, \mathrm{br}), 7.51(\mathrm{~d}, J=7.5 \mathrm{~Hz}$, $3 \mathrm{H}), 7.32-7.21(\mathrm{~m}, 9 \mathrm{H}), 7.09-7.01(\mathrm{~m}, 18 \mathrm{H}), 6.82(\mathrm{t}, J=7.2 \mathrm{~Hz}, 3 \mathrm{H}), 6.55(\mathrm{~s}, 3 \mathrm{H}, \mathrm{br}), 1.92-1.67$ (m, $12 \mathrm{H}), 1.11(\mathrm{~s}, 6 \mathrm{H})$, and $0.97-0.39(\mathrm{~m}, 96 \mathrm{H}) ;{ }^{13} \mathrm{C}-\mathrm{NMR}\left(125 \mathrm{MHz}, \mathrm{CDCl}_{3}\right) \delta 151.9,150.4,149.3$, 147.6, 146.5, 141.0, 136.5, 128.9, 126.7, 126.3, 123.7, 122.7, 121.9, 120.2, 119.1, 115.6, 54.7, 50.9, 50.63, 50.57, 38.0, 37.9, 37.6, 37.5, 33.1, 32.8, 30.9, 30.0, 29.5, 29.3, 27.3, 22.7, and 22.5; MALDI-TOF MS calcd for $\mathrm{C}_{117} \mathrm{H}_{153} \mathrm{~N}_{3}, \mathrm{~m} / z$ 1600.2; found, $\mathrm{m} / z 1601.6\left(\mathrm{MH}^{+}\right)$.

Synthesis of $N^{1}, N^{3}$-Bis(9,9-di(3',5',5'-trimethyl-1'-hexyl)fluoren-2-yl)-1",3",5"-tris(phenylamino)benzene [bis(DPAF-C9), 6]

A mixture of 2-bromo-9,9-bis(3',5',5'-trimethyl-1'-hexyl)fluorene $(0.71 \mathrm{~g}, \quad 1.42 \mathrm{mmol})$, 1,3,5-tris(phenylamino)benzene $(0.25 \mathrm{~g}, \quad 0.71 \mathrm{mmol})$, tris(dibenzylideneacetone)dipalladium $(0)$ $\left[\mathrm{Pd}_{2}(\mathrm{dba}) 3(0), 0.005 \mathrm{~g}, 0.25 \mathrm{~mol} \%\right.$ ], rac-2,2'-bis(diphenylphosphino)-1,1'-binapthyl (BINAP, $0.01 \mathrm{~g}$, $0.75 \mathrm{~mol} \%)$, and sodium $t$-butoxide $(0.70 \mathrm{~g}, 7.10 \mathrm{mmol})$ in anhydrous toluene $(50 \mathrm{~mL})$ was heated to refluxing temperature under nitrogen for $72 \mathrm{~h}$. The reaction mixture was cooled to room temperature and washed with water $(30 \mathrm{~mL})$. The organic layer was dried over anhydrous sodium sulfate. After evaporation of the solvent, it afforded a crude brown colored semi-solid. It was purified by column chromatography using silica gel as the stationary phase and hexane-ethylacetate $(9: 1)$ as the eluent to afford $N^{1}, N^{3}$-bis $(9,9-$ di(3',5',5'-trimethyl-1'-hexyl)fluoren-2-yl)-1",3",5"-tris(phenylamino)benzene, bis(DPAF-C9) 6, as white to light yellow glassy solids in 52\% yield (0.43 g). FT-IR (KBr) vmax $3402(\mathrm{~m}), 3062(\mathrm{w}), 3036(\mathrm{w}), 3010$ (w), 2953 (s), 2865 (m), 1585 (s), 1492 (s), 1467 (m), 1450 (m), 1,422 (w), 1392 (m), 1363 (w), 1299 (m), 
1252 (m), $1213(\mathrm{w}), 1155(\mathrm{w}), 1079(\mathrm{w}), 1033(\mathrm{w}), 824(\mathrm{w}), 738(\mathrm{~m}), 711(\mathrm{w}), 693(\mathrm{~m})$, and $512(\mathrm{w}) \mathrm{cm}^{-1}$; UV-vis $\left(\mathrm{CHCl}_{3}, 1.0 \times 10^{-5} \mathrm{M}\right) \lambda_{\max }(\varepsilon) 308\left(5.56 \times 10^{4}\right)$ and $348 \mathrm{~nm}\left(5.07 \times 10^{4} \mathrm{~L} \mathrm{~mol}^{-1} \mathrm{~cm}^{-1}\right) ; \mathrm{PL}\left(\mathrm{CHCl}_{3}\right.$, $\left.1.0 \times 10^{-5} \mathrm{M}\right) \lambda_{e m, \max } 390.8 \mathrm{~nm} ;{ }^{1} \mathrm{H}-\mathrm{NMR}\left(500 \mathrm{MHz}, \mathrm{CDCl}_{3}\right) \delta 7.61-7.58(\mathrm{~m}, 4 \mathrm{H}), 7.34-7.21(\mathrm{~m}, 7 \mathrm{H}), 7.16$ $(\mathrm{t}, J=7.2 \mathrm{~Hz}, 4 \mathrm{H}), 7.12-7.01(\mathrm{~m}, 10 \mathrm{H}), 6.90(\mathrm{t}, J=6.8 \mathrm{~Hz}, 1 \mathrm{H}), 6.86-6.83(\mathrm{~m}, 2 \mathrm{H}), 6.74(\mathrm{t}, J=6.5 \mathrm{~Hz}$, $1 \mathrm{H}), 6.53(\mathrm{~s}, 1 \mathrm{H}), 6.42(\mathrm{~s}, 2 \mathrm{H}), 5.51(\mathrm{~s}, 1 \mathrm{H}), 1.98-1.71(\mathrm{~m}, 8 \mathrm{H}), 1.21-1.07(\mathrm{~s}, 4 \mathrm{H}, \mathrm{br}), 0.97-0.86(\mathrm{~d}, 4 \mathrm{H})$, and ,0.83-0.34 (m, 60H); ${ }^{13} \mathrm{C}-\mathrm{NMR}\left(125 \mathrm{MHz}, \mathrm{CDCl}_{3}\right) \delta 151.9,150.5,149.6,147.8,146.7,142.5$, 141.0, 136.6, 129.1, 129.0, 126.7, 126.3, 124.1, 123.1, 122.7, 122.0, 120.6, 120.2, 119.1, 117.2, 112.8, 108.10, 108.0, 100.0, 54.8, 50.9, 50.7, 38.0, 37.9, 37.7, 37.6, 33.1, 32.9, 30.9, 29.9, 29.5, 29.30, 29.27, 27.3, 22.6, and 22.5; MALDI-TOF MS calcd for $\mathrm{C}_{86} \mathrm{H}_{109} \mathrm{~N}_{3}, m / z$ 1,183.9; found, $m / z$ 1,184.9 $\left(\mathrm{MH}^{+}\right)$.

Synthesis of $N^{1}$-Mono(9,9-di(3',5',5'-trimethyl-1'-hexyl)fluoren-2-yl)-1",3",5"-tris(phenylamino)benzene [mono(DPAF-C9), 5]

A mixture of 2-bromo-9,9-bis(3',5',5'-trimethyl-1'-hexyl)fluorene $(0.36 \mathrm{~g}, \quad 0.71 \mathrm{mmol})$, 1,3,5-tris(phenylamino)benzene $(0.25 \mathrm{~g}, \quad 0.71 \mathrm{mmol})$, tris(dibenzylideneacetone)dipalladium $(0)$ $\left(\mathrm{Pd}_{2}(\mathrm{dba})_{3}(0), 0.005 \mathrm{~g}, 0.25 \mathrm{~mol} \%\right)$, rac-2,2'-bis(diphenylphosphino)-1,1'-binapthyl (BINAP, $0.01 \mathrm{~g}$, $0.75 \mathrm{~mol} \%)$, and sodium $t$-butoxide $(0.70 \mathrm{~g}, 7.10 \mathrm{mmol})$ in anhydrous toluene $(50 \mathrm{~mL})$ was heated to refluxing temperature under nitrogen for a period of $48 \mathrm{~h}$. The reaction mixture was cooled to room temperature and washed with water $(30 \mathrm{~mL})$. The organic layer was dried over anhydrous sodium sulfate. After evaporation of the solvent, it afforded a crude brown semi-solid. It was purified by column chromatography using silica gel as the stationary phase and hexane-ethylacetate $(9: 1)$ as the eluent then slowly increased ethyl acetate contents up to $30 \%$ to give $N^{1}$-mono(9,9-di(3',5',5'-trimethyl1'-hexyl)fluoren-2-yl)-1",3",5"-tris(phenylamino)benzene, mono(DPAF-C9) 5, as white to light yellow glassy solids in 68\% yield (0.37 g). FT-IR (KBr) $v_{\max } 3396(\mathrm{~m}), 3037(\mathrm{w}), 2952(\mathrm{~s}), 2865(\mathrm{w}), 1585$ (vs), 1518 (w), 1495 (s), 1467 (m), 1450 (m), 1421 (w), 1393 (w), 1363 (w), 1301 (m), 1249 (m), 1171 (w), $1078(\mathrm{w}), 1031(\mathrm{w}), 823(\mathrm{w}), 739(\mathrm{~m}), 692(\mathrm{~m}), 595(\mathrm{w})$, and $514(\mathrm{w}) \mathrm{cm}^{-1}$; UV-vis $\left(\mathrm{CHCl}_{3}, 1.0 \times 10^{-5} \mathrm{M}\right)$ $\lambda_{\max }(\varepsilon) 297\left(5.16 \times 10^{4}\right)$ and $349 \mathrm{~nm}\left(2.64 \times 10^{4} \mathrm{~L} \mathrm{~mol}^{-1} \mathrm{~cm}^{-1}\right) ; \mathrm{PL}\left(\mathrm{CHCl}_{3}, 1.0 \times 10^{-5} \mathrm{M}\right) \lambda_{\text {em, } \max }$ $391.2 \mathrm{~nm} ;{ }^{1} \mathrm{H}-\mathrm{NMR}\left(500 \mathrm{MHz}, \mathrm{CDCl}_{3}\right) \delta$ 7.62-7.58 (m, 2H), 7.33-7.11 (m, 14H), $7.00(\mathrm{~d}, J=7.5 \mathrm{~Hz}$, $4 \mathrm{H}), 6.85(\mathrm{t}, J=7.3 \mathrm{~Hz}, 2 \mathrm{H}), 6.50(\mathrm{~s}, 1 \mathrm{H}), 6.33(\mathrm{~d}, J=1.9 \mathrm{~Hz}, 2 \mathrm{H}), 5.56(\mathrm{~s}, 2 \mathrm{H}), 1.98-1.73(\mathrm{~m}, 4 \mathrm{H}), 1.15$ $(\mathrm{s}, 2 \mathrm{H}), 0.91(\mathrm{~d}, J=13.8 \mathrm{~Hz}, 2 \mathrm{H})$, and $0.84-0.39(\mathrm{~m}, 30 \mathrm{H}) ;{ }^{13} \mathrm{C}-\mathrm{NMR}\left(125 \mathrm{MHz}, \mathrm{CDCl}_{3}\right) \delta 152.0,150.5$, 150.1, 148.0, 146.9, 144.7, 142.7, 141.0, 136.7, 129.3, 129.1, 126.7, 126.4, 124.3, 123.9, 122.7, 122.4, 121.0, 120.3, 119.8, 119.2, 118.0, 105.9, 100.3, 54.8, 51.0, 50.7, 38.0, 37.8, 37.7, 33.2, 33.0, 30.9, 30.0, 29.5, 29.4, 22.6, and 22.5; MALDI-TOF MS calcd for $\mathrm{C}_{117} \mathrm{H}_{153} \mathrm{~N}_{3}, m / z 767.5$; found, $m / z 768.9\left(\mathrm{MH}^{+}\right)$.

\section{Conclusions}

A novel highly luminescent tris-fluorenyl ring-interconnected chromophore tris(DPAF-C9) 7 was designed and synthesized using a $C_{3}$ symmetrical triaminobenzene core as the synthon. The structural moiety bears a close resemblance to that of 2-diphenylamino-9,9-dialkylfluorenyl attachment in the starburst nonlinear photonic materials $\mathrm{C}_{60}\left(>\text { DPAF- } \mathrm{C}_{\mathrm{n}}\right)_{\mathrm{x}}$, reported previously [33-36]. The synthetic chromophore 7 was chromatographically purified and characterized as a major stereoisomer possessing a 3D structural configuration of the cis-cup-conformer showing symmetrical phenyl protons of the central benzene ring. A molecular calculated structure of 7 at B3LYP/6-31G* level of theory based on 
the optimized 3D structure indicated the unexpected stability of the cup-form as explained by the dihedral torsional angle of the central benzene ring that revealed much less angle strain than that of the stereoisomer in a propeller-form. Angle strain of the trans-chair-conformer was found to be higher by the same calculation due to the unavoidable unsymmetrical conformation. These analyses provided the explanation on the exclusive isolation of highly symmetrical cis-cup-conformer of tris(DPAF-C9). The fluorescent emission wavelength of cis-tris(DPAF-C9) was found in a close range to that of PVK with slightly lower HOMO $(-4.81 \mathrm{eV})$ than that of $\operatorname{Ir}(\mathrm{ppy})_{3}(-4.9 \mathrm{eV})$. Therefore, this donor chromophore may serve as the secondary blue hole-transporting material, which is capable of minimizing the aggregation-related self-quenching effect, in the modulation of PLED performance.

\section{Supplementary Materials}

Supplementary materials can be accessed at: http://www.mdpi.com/1420-3049/20/03/4635/s1.

\section{Acknowledgments}

The authors at UML thank the financial support of Air Force Office of Scientific Research (AFOSR) under the grant number FA9550-09-1-0380, FA9550-09-1-0183, and FA9550-14-1-0153. The author at GIST thanks the financial support of the Ministry of Education, Science and Technology (MEST) under Basic Science Research Program (Project no. 2011-0026341).

\section{Author Contributions}

All authors contribute a significant effort on this work. NGK, SJ, MW, and TC carried out synthetic works, spectroscopic characterization, and data analysis; CLL carried out device fabrication, performance evaluation, and physical property characterization; KK performed molecular simulation, energy calculation, and a part of manuscript drafting; All authors read and approved the final manuscript.

\section{Conflicts of Interest}

The authors declare no conflict of interest.

\section{References}

1. Shimizu, M.; Hiyama, T. Organic fluorophores exhibiting highly efficient photoluminescence in the solid state. Chem. Asian J. 2010, 5, 1516-1531.

2. Kalinowski, J. Organic Light-Emitting Diodes: Principles, Characteristics \& Processes; CRC Press: New York, NY, USA, 2004.

3. Leo, K. Organic LEDs look forward to a bright, white future. Science 2005, 310, 1762-1763.

4. Sun, Y.; Giebink, N.; Kanno, H.; Wa, B.; Thompson, M.E.; Forrest, S.R. Management of singlet and triplet excitons for efficient white organic light-emitting devices. Nature 2006, 440, 908-912.

5. He, G.S.; Tan, L.-S.; Zheng, Q.; Prasad, P.N. Multiphoton absorbing materials: Molecular designs, characterizations, and applications. Chem. Rev. 2008, 108, 1245-1330.

6. Lee, K.-S.; Kim, R.H.; Yang, D.-Y.; Park, S.H. Advances in 3D nano/microfabrication using two-photon initiated polymerization. Prog. Polym. Sci. 2008, 33, 631-681. 
7. Yao, S.; Belfield, K.D. Two-photon fluorescent probes for bioimaging. Eur. J. Org. Chem. 2012, 3199-3217.

8. Pawley, J.B. Handbook of Biological Confocal Microscopy; Plenum Press: New York, NY, USA, 1995.

9. Fan, J.; Hu, M.; Zhan, P.; Peng, X. Energy transfer cassettes based on organic fluorophores: construction and applications in ratiometric sensing. Chem. Soc. Rev. 2013, 42, 29-43.

10. Serin, J.M.; Brousmiche, D.W.; Frechet, J.M.J. A FRET-based ultraviolet to near-infrared frequency converter. J. Am. Chem. Soc. 2002, 124, 11848-11849.

11. Brousmiche, D.W.; Serin, J.M.; Frechet, J.M.J.; He, G.S.; Lin, T.C.; Chung, S.J.; Prasad, P.N. Fluorescence resonance energy transfer in a novel two-photon absorbing system. J. Am. Chem. Soc. 2003, 125, 1448-1449.

12. Sharma, S.K.; Chiang, L.Y.; Hamblin, M.R. Photodynamic therapy with fullerenes in vivo: Reality or a dream? Nanomedicine 2011, 6, 1813-1825.

13. Huang, Y.Y.; Sharma, S.K.; Dai, T.; Chung, H.; Yaroslavsky, A.; Garcia-Diaz, M.; Chang, J.; Chiang, L.Y.; Hamblin, M.R. Can nanotechnology potentiate photodynamic therapy? Nanotechnol. Rev. 2012, 1, 111-146.

14. Hu, R.; Lager, E.; Aguilar-Aguilar, A.; Liu, J.; Lam, J.W.Y.; Sung, H.H.Y.; Williams, I.D.; Zhong, Y.; Wong, K.S.; Pena-Cabrera, E.; et al. Twisted intramolecular charge transfer and aggregation-induced emission of BODIPY derivatives. J. Phys. Chem. C 2009, 113, 15845-15853.

15. Kim, S.; Pudavar, H.E.; Bonoiu, A.; Prasad, P.N. Aggregation-enhanced fluorescence in organically modified silica nanoparticles: A novel approach toward high-signal-output nanoprobes for two-photon fluorescence bioimaging. Adv. Mater. 2007, 19, 3791-3795.

16. Kim, S.; Zheng, Q.; He, G.S.; Bharali, D.J.; Pudavar, H.E.; Baev, A.; Prasad, P.N. Aggregationenhanced fluorescence and two-photon absorption in nanoaggregates of a 9,10-bis[4'-(4"aminostyryl)styryl]anthracene derivative. Adv. Funct. Mater. 2006, 16, 2317-2323.

17. Abbotto, A.; Beverina, L.; Bozio, R.; Facchetti, A.; Ferrante, C.; Pagani, G.A.; Pedron, D.; Signorini, R. Novel heteroaromatic-based multi-branched dyes with enhanced two-photon absorption activity. Chem. Commun. 2003, 2144-2145.

18. Macak, P.; Luo, Y.; Norman, H.; Ågren, H. Electronic and vibronic contributions to two-photon absorption of molecules with multi-branched structures. J. Chem. Phys. 2000, 113, 7055-7061.

19. Belfield, K.D.; Morales, A.R.; Hales, J.M.; Hagan, D.J.; van Stryland, E.W.; Chapela, V.M.; Percino, J. Linear and two-photon photophysical properties of a series of symmetrical diphenylaminofluorenes. Chem. Mater. 2004, 16, 2267-2273.

20. Porres, L.; Mongin, O.; Katan, C.; Charlot, M.; Pons, T.; Mertz, J.; Blanchard-Desce, M. Enhanced two-photon absorption with novel octupolar propeller-shaped fluorophores derived from triphenylamine. Org. Lett. 2004, 6, 47-50.

21. Kannan, R.; He, G.S.; Lin, T.-C.; Prasad, P.N.; Vaia, R.A.; Tan, L.-S. Toward highly active two-photon absorbing liquids. Synthesis and characterization of 1,3,5-triazine-based octupolar molecules. Chem. Mater. 2004, 16, 185-194.

22. Collings, J.C.; Poon, S.-Y.; Droumaguet, C.L.; Charlot, M.; Katan, C.; Pålsson, L.-O.; Beeby, A.; Mosely, J.A.; Kaiser, H.M.; Wong, W.-Y.; et al. The synthesis and one- and two-photon optical properties of dipolar, quadrupolar and octupolar donor-acceptor molecules containing dimesitylboryl groups. Chem. Eur. J. 2009, 15, 198-208. 
23. Adronov, A.; Frechet, J.M.; He, G.S.; Kim, K.-S.; Chung, S.-J.; Swiatkiewicz, J.; Prasad, P.N. Novel two-photon absorbing dendritic structures. Chem. Mater. 2000, 12, 2838-2841.

24. Drobizhev, M.; Karotki, A.; Rebane, A.; Spangler, C.W. Dendrimer molecules with record large two-photon absorption cross section. Opt. Lett. 2001, 26, 1081-1083.

25. Hua, J.L.; Li, B.M.; Fan, S.; Ding, F.; Qian, S.X.; Tian, H. Two-photon absorption properties of hyperbranched conjugated polymers with triphenylamine as the core. Polymer 2004, 45, 7143-7149.

26. Lo, S.-C.; Burn, P.L. Development of dendrimers: Macromolecules for use in organic light-emitting diodes and solar cells. Chem. Rev. 2007, 107, 1097-1116.

27. Saragi, T.P.I.; Spehr, T.; Siebert, A.; Fuhrmann-Lieker, T.; Salbeck, J. Spiro compounds for organic optoelectronics. Chem. Rev. 2007, 107, 1011-1065.

28. Burn, P.L.; Lo, S.-C.; Samuel, I.D.W. The development of light-emitting dendrimers for displays. Adv. Mater. 2007, 19, 1675-1688.

29. Shirota, Y.; Kageyama, H. Charge carrier transporting molecular materials and their applications in devices. Chem. Rev. 2007, 107, 953-1010.

30. Chiang, L.Y.; Padmawar, P.A.; Canteenwala, T.; Tan, L.-S.; He, G.S.; Kannan, R.; Vaia, R.; Lin, T.-C.; Zheng, Q.; Prasad, P.N. Synthesis of C60-diphenylaminofluorene dyad with large 2PA cross-sections and efficient intramolecular two-photon energy transfer. Chem. Commun. 2002, $1854-1855$.

31. Ishikawa, W.; Ikeda, H.; Nakano, H.; Shirota, Y. Methyl-substituted derivatives of 1,3,5-tris(diphenylamino)benzene as a novel class of amorphous molecular materials. Chem. Lett. 1991, 20, 1731-1734.

32. Inada, H.; Shirota, Y. 1,3,5-Tris[4-(diphenylamino)phenyl]benzene and its methyl-substituted derivatives as a novel class of amorphous molecular materials. J. Mater. Chem. 1993, 3, 319-320.

33. Padmawar, P.A.; Canteenwala, T.; Tan, L.-S.; Chiang, L.Y. Synthesis and characterization of photoresponsive diphenylaminofluorene chromophore adducts of [60]fullerene. J. Mater. Chem. 2006, 16, 1366-1378.

34. Padmawar, P.A.; Rogers, J.O.; He, G.S.; Chiang, L.Y.; Canteenwala, T.; Tan, L.-S.; Zheng, Q.; Lu, C.; Slagle, J.E.; Danilov, E.; et al. Large cross-section enhancement and intramolecular energy transfer upon multiphoton absorption of hindered diphenylaminofluorene- $\mathrm{C}_{60}$ dyads and triads. Chem. Mater. 2006, 18, 4065-4074.

35. Elim, H.I.; Anandakathir, R.; Jakubiak, R.; Chiang, L.Y.; Ji, W.; Tan, L.S. Large concentration-dependent nonlinear optical responses of starburst diphenylaminofluorenocarbonyl methano[60]fullerene pentads. J. Mater. Chem. 2007, 17, 1826-1838.

36. El-Khouly, M.E.; Anandakathir, R.; Ito, O.; Chiang, L.Y. Prolonged charge-separated states of starburst tetra(diphenylaminofluoreno)[60]fullerene adducts upon photoexcitation. J. Phys. Chem. A 2007, 111, 6938-6944.

Sample Availability: Samples are not available from the authors.

(C) 2015 by the authors; licensee MDPI, Basel, Switzerland. This article is an open access article distributed under the terms and conditions of the Creative Commons Attribution license (http://creativecommons.org/licenses/by/4.0/). 